\title{
Exposure to Armed Conflict and Fertility in Sub-Saharan Africa
}

\author{
Brian C. Thiede ${ }^{1}$, Pennsylvania State University \\ Matthew Hancock, Pennsylvania State University \\ Ahmed Kodouda, George Washington University \\ James Piazza, Pennsylvania State University
}

March 2020

Forthcoming at Demography

\begin{abstract}
Changes in fertility patterns are hypothesized to be among the many second-order consequences of armed conflict, but expectations about the direction of such effects are theoretically ambiguous. Prior research, from a range of contexts, has also yielded inconsistent results. We contribute to this debate by using harmonized data and methods to examine the effects of exposure to conflict on preferred and observed fertility outcomes across a spatially and temporally extensive population. We use high-resolution georeferenced data from 25 subSaharan African countries, combining records of violent events from the Armed Conflict Location and Event Dataset with data on fertility goals and outcomes from the Demographic and Health Surveys ( $\mathrm{n}=368,765$ women aged $15-49$ years). We estimate a series of linear and logistic regression models to assess the effects of exposure to conflict events on ideal family size and the probability of childbearing within the 12 months prior to the interview. We find that, on average, exposure to armed conflict leads to modest reductions in both respondents' preferred family size and their probability of recent childbearing. Many of these effects are heterogeneous between demographic groups and across contexts, which suggests systematic differences in women's vulnerability or preferred responses to armed conflict. Additional analyses suggest that conflict-related fertility declines may be driven by delays or reductions in marriage. These results contribute new evidence about the demographic effects of conflict and their underlying mechanisms, and broadly underline the importance of studying the many second-order effects of organized violence on vulnerable populations.
\end{abstract}

\section{Keywords}

Fertility, Fertility Preferences, Marriage, Armed Conflict, Africa

\section{Acknowledgements}

Thanks to Yosef Bodovski and Matthew Brooks for programming assistance. Thiede acknowledges the assistance provided by the Population Research Institute at Penn State, which is supported by an infrastructure grant from the Eunice Kennedy Shriver National Institute of Child Health and Human Development (P2CHD041025). Thiede and Piazza also acknowledge support from the Penn State Social Science Research Institute and the Penn State Center for Security Research and Education.

${ }^{1}$ Corresponding author: 111A Armsby Building, The Pennsylvania State University, University Park, PA 16802; Email: bct11@psu.edu; Phone: 814-865-2561. 


\begin{abstract}
Changes in fertility patterns are hypothesized to be among the many second-order consequences of armed conflict, but expectations about the direction of such effects are theoretically ambiguous. Prior research, from a range of contexts, has also yielded inconsistent results. We contribute to this debate by using harmonized data and methods to examine the effects of exposure to conflict on preferred and observed fertility outcomes across a spatially and temporally extensive population. We use high-resolution georeferenced data from 25 sub-Saharan African countries, combining records of violent events from the Armed Conflict Location and Event Dataset with data on fertility goals and outcomes from the Demographic and Health Surveys ( $n=368,765$ women aged 15-49 years). We estimate a series of linear and logistic regression models to assess the effects of exposure to conflict events on ideal family size and the probability of childbearing within the 12 months prior to the interview. We find that, on average, exposure to armed conflict leads to modest reductions in both respondents' preferred family size and their probability of recent childbearing. Many of these effects are heterogeneous between demographic groups and across contexts, which suggests systematic differences in women's vulnerability or preferred responses to armed conflict. Additional analyses suggest that conflict-related fertility declines may be driven by delays or reductions in marriage. These results contribute new evidence about the demographic effects of conflict and their underlying mechanisms, and broadly underline the importance of studying the many second-order effects of organized violence on vulnerable populations.
\end{abstract}




\section{Introduction}

Armed conflict disrupts many domains of life beyond the immediate effects of violence and insecurity (Ghobarah et al. 2003; Caldwell 2004). Exposure to such events has been linked to adverse social and demographic outcomes, including poor child and adult health (Akresh et al. 2012; Minoiu and Shemyakina 2014; Torche and Shwed 2015), migration and displacement (Verwimp and van Bavel 2004; Adhikari 2012; Bohra-Mishra and Massey 2011; Czaika and KisKatos 2009; Williams et al. 2012; Williams 2015), and declines in economic activity (World Bank 2011). Demographers have also hypothesized that conflict may affect reproductive goals and behaviors through mechanisms that include shifting patterns of marriage and spousal separation (Caldwell 2004; Blanc 2004; Cetorelli 2014), changing the relative costs and risks of childbearing (Lindstrom and Berhanu 1999), inducing replacement effects in response to conflict-related mortality (Schindler and Brück 2011), and increasing the risk of sexual violence and intrahousehold conflict (Corno et al. 2017). However, these processes may not operate in a consistent manner, resulting in competing hypotheses about the strength and sign of conflict effects. Tests of these expectations, across a range of contexts, have yielded inconsistent results with respect to both the presence and direction of the relationship between conflict and fertility.

We contribute evidence to this literature and extend prior research by using georeferenced demographic and conflict data to evaluate the association between armed conflict and both fertility ideals and outcomes across a temporally and spatially extensive population of reproductive-aged women in sub-Saharan Africa (Boyle et al. 2018; Raleigh et al. 2010). Importantly, these data allow us to construct and employ new high-resolution measures of women's exposure to conflict events. As such, we build upon existing research by simultaneously 'zooming out' to study the demographic effects of conflict across a large target population, and 'zooming in' to measure 
conflict exposure at the spatial and temporal scales at which conflict events unfold and many of the processes linking conflict and fertility operate (Buhaug and Rød 2006; Williams et al. 2012).

The evidence we generate through this approach makes new theoretical contributions and has the potential to broadly inform development and humanitarian work as it relates to mitigating the second-order impacts of conflict. For one, we study the links between conflict and fertility across a large sample and using harmonized data and methods. This approach permits us to estimate average effects across an extensive population and to compare effects across subpopulations and contexts. Such comparisons are not confounded by differences in data and methods, as is often the case when comparing findings across single-country studies. By examining heterogeneous effects, our analyses provide insights into whether and how women vary in terms of their level of vulnerability (resilience) to conflict, as well as in their ability and propensity to modify fertility in response to such events. Relatedly, we examine hypothesized mechanisms linking conflict and fertility, providing empirical evidence about which explanatory processes are most salient. Our findings may also have broader implications for theories of fertility by informing expectations about the demographic effects of comparable shocks to populations' health and wealth.

The results of this study are of practical interest given persistently high and increasing levels of political instability throughout the world, and the corollary need to mitigate the effects of these events (World Bank 2011). It is important for policymakers and practitioners to consider the secondary effects of conflict-including changes in reproductive goals and outcomes — which can have persistent if not always immediate consequences for affected populations (Ghobarah et al. 2003). These issues are particularly pertinent to the sub-Saharan African context that we consider here. Over recent decades, the region has experienced significant levels of conflict, resulting in at 
least 428,000 deaths since 2000 alone (ACLED 2019). ${ }^{1}$ While the dynamics of individual conflicts are often unique, the countries in our sample share of legacy of weak state institutions and chronic political instability that, in most cases, stems in part from prolonged periods of European rule (World Bank 2018). ${ }^{2}$ These characteristics have manifest in unique conflict dynamics in the region vis-à-vis other parts of the world, in terms of both the frequency and types of conflict that have occurred. For example, African conflicts in the post-Cold War era have often been so-called repeat civil wars, involved contestation of government transitions, and included complex sets of domestic and international state and non-state actors (Williams 2017). Sub-Saharan Africa is also characterized by a distinctive set of demographic dynamics, with persistently high, if heterogeneous, birth rates across the continent (Bongaarts and Casterline 2013). For example, the most recent data from the Demographic and Health Survey (DHS) reveal total fertility rates above 4.0 in most African countries, but with a range from 7.6 in Niger to 3.3 in Lesotho. Given these high average birth rates, the region will continue to account for a disproportionate share of global population growth into the future (Gerland et al. 2014).

In this paper, we consider the relationship between these distinctive patterns of conflict and fertility in sub-Saharan Africa. We do so by estimating the effects of localized exposure to conflict on both fertility ideals and outcomes among women in 25 sub-Saharan African countries between 2000 and 2017. Our paper proceeds as follows. In the next section, we describe the conceptual framework and previous empirical findings that motivate our study. We subsequently define our specific research objectives and hypotheses, and describe the data and methods employed. We next

\footnotetext{
${ }^{1}$ The casualty figure is for all African countries from January 1, 2000 to January 1, 2018 and includes deaths from intrastate and interstate conflicts, violent protests, terrorism, and government violence against civilians.

${ }^{2}$ Evidence of such weak institutions and political instability comes from the World Bank's Governance Effectiveness and Political Stability and Absence of Violence indicators. Both indicators range between -2.50 to 2.50. For 19962018, our sample's mean score for Governance Effectiveness is -0.75 and for Political Stability and Absence of Violence is -0.65 .
} 
present our results, focusing first on how conflict affects ideal family size and recent fertility outcomes, next on the possible mechanisms linking conflict and fertility, and finally on a series of robustness checks. We conclude by discussing the broader implications of our findings and identifying areas for future research.

\section{Conflict and Fertility}

Disruptions associated with armed conflict and other forms of political instability have been hypothesized to change the incentives for, and likelihood of, childbearing in affected populations. Such changes are expected to operate through multiple mechanisms, which function in complex and potentially offsetting ways. In stylized terms, these pathways can be separated into four sets of factors: shifts in patterns of marriage and co-residence; changes in the relative costs and risks of childbearing; replacement effects; and the consequences of sexual violence. First, conflict may change patterns of marriage and co-residence by shifting the incentive structure for marriage and changing the likelihood and duration of spousal separation (Caldwell 2004; Woldemicael 2010; Cetorolli 2012; Williams et al. 2012). For instance, spouses may separate as some household members - typically working-age men — are recruited into the military or militia groups, or if conflict-induced migration patterns lead to the separation of household members (McGinn 2000; Agadjanian et al. 2011; Verwimp and van Bavel 2004). Similarly, persons who are displaced by conflict or mobilized for military activity may be less likely to marry given uncertainty associated with such events and the limited marriage markets among displaced populations and groups of combatants. Marriage markets may also be disrupted if bride prices or other costs of marriage change, or the resources to pay such costs are lost due to conflict (Corno et al. 2017). The 
incentives for marriage may also change due to threat of military mobilization, particularly if unmarried males are targeted for recruitment (Williams et al. 2012).

Second, conflict may affect fertility goals and behaviors by changing the relative costs and risks of childbearing. Economic dynamics may spur some of these changes. Conflict often reduces wealth among affected households (Collier et al. 2003), which can in turn shape the calculus of fertility decision-making. Economic uncertainties that are associated with armed conflict may incentivize individuals to have additional children if those children are perceived as likely to increase future income levels or otherwise provide economic support (Berrebi and Ostwald 2015). Alternatively, women may perceive an additional child as unaffordable under conflict-induced income constraints if children are viewed as net consumers of household resources. Conflict may also affect the relative benefits of childbearing by influencing the costs of controlling fertility via changing access to contraceptives. Here, conflict is generally expected to disrupt access to contraceptives (McGinn et al. 2011; Urdal and Che 2013), and in some cases protracted violence may induce pro-natalist sentiments that increase the social costs of limiting fertility (Palmer and Storeng 2016). Conflict may further change the costs and risk of childbearing in terms of maternal and child health, often adversely due to disruptions in healthcare access (Lindskog 2016; McGinn et al. 2011; Øtsby et al. 2018). In these and perhaps other ways, conflict is expected to affect demographic outcomes by elevating perceptions of uncertainty across many dimensions of life (Caldwell 2004).

Third, exposure to violence may change fertility goals and outcomes by inducing replacement effects, or increases in fertility in response to mortality. Such responses may be driven by the mortality of one's child or family member, as was observed in the aftermath of the Rwandan genocide (Kraehnert et al. 2019; Schindler and Brück 2011). Replacement-effect dynamics may 
also occur at the community or group level, such as when post-conflict community-building efforts or a desire to increase ethnic group size lead to pro-natalist sentiment (Chi et al. 2015; Palmer and Storeng 2016). ${ }^{3}$ While the evidence for replacement effects in conflict settings is limited, similar processes have been observed in response to child deaths in other settings, such as those caused by disease and natural disasters (Olsen 1980; Bongaarts 2001; Lindstrom and Kiros 2007; Hossain et al. 2007; Nobles et al. 2015).

Finally, armed conflict may affect fertility by increasing the incidence of sexual violence (McGinn 2000). Rape and other sexual assault have been used as a tool of warfare in many conflicts in sub-Saharan Africa, including in recent civil conflicts in the Democratic Republic of Congo, Ethiopia, and Sudan (Hagan et al. 2009; Human Rights Watch 2008; Peterman et al. 2011). In addition to the perpetration of such violence by combatants, conflict has also been shown to increase intimate partner sexual violence through both psychological and socioeconomic pathways (Østby 2016; Wood 2014). In either case, these crimes may influence fertility directly by resulting in pregnancies and indirectly by affecting victim's physical and mental health (Dossa et al. 2014; Pallitto and O'Campo 2004).

These four sets of pathways can plausibly explain the relationship between conflict and fertility, but do not suggest clear directional hypotheses since they may operate in different strengths and directions. In line with this conceptual ambiguity, the empirical record is inconsistent with respect to the direction of conflict effects. Several studies find that conflict reduces fertility. For example, fertility rates declined during periods of conflict in Angola (Agadjanian and Prata 2002) and Mozambique (Agadjanian et al. 2011), and periods of concurrent war and famine in

\footnotetext{
${ }^{3}$ Fertility may also increase in response to perceived child mortality risk due to conflict (i.e., "insurance effects"). However, such processes would require women to perceive that conflict will increase mortality risk over sustained periods of time, which has not been demonstrated empirically.
} 
Ethiopia were associated with short-term declines in the probability of conception (Lindstrom and Berhanu 1999). Likewise, a secular decline in fertility in Eritrea was likely amplified by the 19982000 war with Ethiopia (Woldemicael 2010). According to an empirical study of terrorist attacks in 170 countries between 1970 and 2007, terrorism has also been linked to declines in the total fertility rate (TFR) and crude birth rates (CBR) (Berrebi and Otswald 2015). Finally, violent conflicts were associated with an increase in contraceptive use — and thus presumable decreases in fertility—during a civil war in Nepal (Williams et al. 2012).

Other studies have found the opposite: that fertility rates increase during episodes of armed conflict. For instance, conflict intensity in sub-Saharan Africa, measured as battle-related deaths, has been associated with increases in national fertility rates among the poorest countries in the region (Urdal and Che 2013). There is also evidence from the Iraqi context of a sharp increase in fertility rates among women ages 15 to 24 following the 2003 U.S. invasion and subsequent civil conflict (Cetorolli 2015); and violent events during the Colombian civil war were associated with increased fertility in the rural areas where conflict was widespread (Torres and Urdinola 2019). In a final example, Cambodian women's exposure to conflict during adolescence has been linked to later-life fertility (Islam et al. 2015).

We contribute to this debate by conducting new tests of the relationship between conflict and fertility across sub-Saharan Africa and addressing existing limitations regarding the precision of conflict exposure measures and the ability to compare effects across sub-populations. Many previous studies have drawn inferences about the effects of conflict by tracking changes in national fertility rates before, during, and after a given conflict (Woldemicael 2008, 2010; Schindler and Brück 2011) or comparing fertility dynamics between more- and less-affected regions within 
countries (Lindstrom and Berhanu 1999). In either case, such national or province-level measures of conflict and fertility are likely to mask substantial spatial variation.

A number of recent studies have overcome these measurement challenges by using georeferenced conflict data to produce measures of violence for sub-national administrative units (e.g., districts), and examining the relationship between conflict exposure (so defined) and demographic outcomes (Dabalen and Paul 2014; Lindskog 2016; Minoiu and Shemyakina 2012). These analyses improve upon measurement of conflict exposure by accounting for spatial heterogeneity within countries but tend to rely on inconsistently sized, and sometimes large, administrative units. These studies have also focused on narrow geographic contexts (i.e., single countries), making it difficult to draw comparisons given methodological differences. ${ }^{4}$ Using high-resolutions measures of conflict, we apply harmonized data and methods to examine the effects of conflict on fertility across 25 sub-Saharan African countries and among key sub-populations. Such findings contribute to theory-building and can shape expectations about the demographic implications of recent trends in conflict across the continent.

\section{Research Objectives}

The overalls goals of this study are to estimate the associations between exposure to armed conflict and both preferred and recent fertility outcomes, and to explore the mechanisms that may underlie these relationships. We consider both reproductive preferences and outcomes, in part because the effects of conflict on the latter may be attenuated by some women's inability to act upon conflictinduced changes in fertility preferences. For example, a lack of access to contraceptives will reduce one's likelihood of realizing conflict-induced declines in fertility preferences; or conversely,

\footnotetext{
${ }^{4}$ One study that has used high-resolution conflict and demographic data across a large multi-national context focused on maternal and child health rather than fertility (Øtsby et al. 2018).
} 
spousal separation will prevent women from realizing increases in preferred family size. We take the nature and degree of such attenuation as an empirical question for our study.

Towards our overall goal, we take the following five steps: First, we analyze the overall association between exposure to armed conflict and women's family size preferences. Second, we test for variation in conflict effects between demographic groups and across contexts, defined by educational attainment, parity, rural or urban residence, and reproductive setting as proxied by the national total fertility rate. We also report the results of complementary country-specific models. As our third and fourth steps, we conduct a parallel set of analyses of the overall and group-specific associations between conflict and achieved fertility outcomes, operationalized as the probability of childbearing during the 12 months prior to the survey. Finally, we explore the pathways that may underlie the observed relationships (or lack thereof). We estimate parallel models of the respective associations between conflict and child mortality, marriage, and contraceptive use, which represent three plausible mechanisms underlying conflict-fertility relationships.

\section{Empirical Strategy}

\section{Data}

We construct a multi-country and multi-decade database that includes records of women's fertility ideals and outcomes, their demographic and socioeconomic characteristics, and their exposure to armed conflict events. We draw on demographic and socioeconomic data for reproductive-age women (ages 15-49 years) from a series of DHS surveys fielded between 2000 and 2017. The DHS program has collected nationally-representative demographic and population health data across many low- and middle-income countries, with multiple rounds of cross-sectional data collected in 
many of those places. ${ }^{5}$ DHS data are collected using a standardized core questionnaire, which facilitates harmonization across contexts and makes these data particularly well-suited for our multi-country sample. ${ }^{6}$ Our measures of armed conflict are derived from the Armed Conflict Location and Event Dataset (ACLED). The ACLED Project collects, analyzes, and maps the incidence and characteristics of a range of violent events, from inter-state battles to riots and other forms of civil unrest (Raleigh et al. 2010). We use ACLED data on the date and location (latitude/longitude) of conflict events in sub-Saharan Africa, which are currently available from 1997 to the present.

Among the DHS samples that have been collected in the region, we restrict the analytic sample to countries and years for which conflict event data are available for at least three years prior to the DHS survey (i.e., years $\geq 2000$ ) to allow for a 36-month lookback period for conflict exposure measures. We also restrict our analysis to samples for which geocodes are available at the cluster (i.e., community) level and that include information on women's time of residence in their cluster of enumeration. The former allows us to calculate the number of conflict events that occurred within a given radius of individuals' clusters of residence during the time intervals of interest. Using the latter, we can exclude all recent in-migrants, defined as women who did not reside in the cluster of enumeration throughout the entire period of conflict exposure. We exclude these observations since such recent in-migrants were exposed to other unobservable levels of conflict in their place of prior residence and may differ systematically from the population that resided in a cluster for the entire exposure interval. Individuals who migrated or were displaced from the enumeration areas due to conflict and before data collection cannot be observed in the

\footnotetext{
${ }^{5}$ DHS estimates are nationally representative when survey weights are applied.

${ }^{6}$ The DHS has implemented multiple phases of the survey, and in some cases responses options are tailored to the local context. However, the datasets and variables included in our analytic sample were sufficiently alike to permit harmonization.
} 
sample given the cross-sectional design of the DHS. These out-migrants are likely to be positively selected on socioeconomic characteristics, and therefore have below-average levels of fertility. Such dynamics would bias our estimates of conflict effects upwards, which we consider in the discussion of results. After these restrictions, our dataset includes a total of 368,765 observations from 41 DHS samples collected in 25 sub-Saharan African countries between 2000 and 2017. ${ }^{7}$ The sample is described in Table 1, and the geographic distribution of the DHS clusters in our analytic sample is illustrated in Figure 1. ${ }^{8}$

(Table 1)

(Figure 1)

\section{Measures}

\section{Main analysis}

We focus on two primary outcomes in this study: ideal family size and recent fertility. We model ideal family size to capture women's preferred fertility outcomes regardless of their ability to achieve that goal. This first dependent variable represents the number of children that the woman would ideally like to have in her lifetime, irrespective of actual childbearing. ${ }^{9}$ We use this variable as our preferred measure of women's reproductive goals since it theoretically allows for downward revisions below one's achieved fertility, which questions about preferences for another child do

\footnotetext{
7 The countries (samples) in our data are as follows: Angola (2015), Benin (2001), Burkina Faso (2003), Burundi (2016), Cameroon (2004), Democratic Republic of the Congo (2007), Eswatini (2006), Ethiopia (2000), Ethiopia (2005), Ethiopia (2016), Ghana (2003), Ghana (2006), Guinea (2005), Kenya (2003), Kenya (2008-09), Lesotho (2004), Lesotho (2009), Liberia (2007), Madagascar (2008), Malawi (2000), Malawi (2004), Malawi (2010), Malawi (2016), Mali (2001), Mali (2006), Namibia (2000), Namibia (2006), Nigeria (2003), Nigeria (2008), Rwanda (2005), Senegal (2005), Sierra Leone (2008), Tanzania (2004), Tanzania (2015), Uganda (2001), Uganda (2006), Uganda (2016), Zambia (2007), Zambia (2013), Zimbabwe (2005-06), Zimbabwe (2015).

${ }^{8}$ See Table A1 for the distribution of observations by country and the proportion of each sample exposed to conflict, as defined in the main specification.

${ }^{9}$ We exclude non-numeric responses (e.g., "up to God") from the analysis. The prevalence of such responses is typically less than 10 percent and has declined over time in sub-Saharan Africa (Frye and Bachan 2017).
} 
not. While ideal family size has been shown to be a meaningful construct for capturing changes in women's reproductive goals (Yeatmen et al. 2013), we test the robustness of our findings by using a categorical fertility preference outcome in a supplementary analysis. The results of these models (see below) demonstrate that our substantive conclusions are not driven by the choice of outcome variable or patterns of non-numeric responses about ideal family size.

Our second outcome of interest is recent fertility, which we measure using a binary indicator of whether a woman gave birth to a child during the 12 months prior to the survey. We use this cross-sectional measure of fertility (rather than the DHS birth histories) to facilitate direct comparison between our analyses of ideal family size and fertility outcomes. As described above, we expect that the association between conflict and fertility will be attenuated vis-à-vis the association of conflict with preferred family size given heterogeneity in women's ability to realize conflict-affected changes in preferences.

The independent variable of interest is exposure to armed conflict, operationalized as a binary of indicator of whether one or more violent conflict events took place within a 10-kilometer radius of women's communities of residence during the 36 months prior to data collection. This approach follows other demographic research (Williams et al. 2012) by focusing on exposure to discrete violent incidents - that is, one of the multiple events that typically constitute broader military conflicts. We define conflict events to include battles and incidents of remote violence. ${ }^{10}$ Battles are violent events involving politically organized, armed state or non-state actors. Examples include armed clashes between state security forces and insurgents, insurgent capture of territory through force, and state recapture of territory controlled by rebels. Incidents of remote

\footnotetext{
${ }^{10}$ ACLED includes other categories of violent events such as violence against civilians and violent protests or riots. We exclude such events for two reasons. First, we are interested in the effects of armed conflict specifically rather than unrest and instability in general. Second, comparable measures for these types of violence are not available in the UCDP database, which we use to test the robustness of our findings with ACLED.
} 
violence are nonconventional violent acts where the mode of attack does not require the perpetrator's physical presence, such as terrorist bombings, the use of improvised explosive devices (IEDs), shelling, and airstrikes. There is no minimum number of casualties required for an event to be classified as a battle or remote attack. Therefore, these measures capture instances of both high- and low-intensity violence.

We measure conflict events within a 10-kilometer buffer with the goal of capturing events that directly impacted women, their families, and members of their social networks. ${ }^{11,12}$ Our use of a 36-month lookback period allows sufficient time to capture lagged effects. For example, when modeling childbearing in the prior year, our measure will on average capture 21 months of conflict exposure prior to conception. ${ }^{13}$ Since there is little existing evidence to guide these specific decisions, however, we test the sensitivity of our results to the use of alternative measures of conflict exposure. The results of these and other robustness checks are included in the Online Supplementary Information.

\section{Mechanisms}

To explore the mechanisms that may underlie observed relationships between conflict and reproductive outcomes, we conduct parallel analyses of the associations between conflict and three outcomes that correspond to hypothesized causal pathways: the recent death of a child, marriage

\footnotetext{
${ }^{11}$ We account for the error around GPS coordinates in the public-use DHS data by defining a 10-kilometer radius as the minimum buffer in our analysis. The DHS program randomly displaces the GPS coordinates for all clusters to maintain confidentiality. The coordinates for urban clusters are displaced by $0-2$ kilometers, and rural clusters by $0-5$ kilometers, with 1 percent of rural clusters displaced by 0-10 kilometers (Burgert et al. 2013). Our approach is consistent with the approach of other high-quality sources, including the DHS program's own geospatial dataset and IPUMS-DHS.

${ }^{12}$ Some countries and regions in the sample did not experience conflict events during the study period. We check the robustness of our results to excluding these places from the analytic sample in Models A1-A4 in the Online Supplementary Information.

${ }^{13}$ We assume a 9-month gestational period and that the average birth during the prior 12 months occurred at the mid-point of the interval.
} 
or cohabitation, and contraceptive use. First, we measure child deaths using a binary indicator of whether one or more of a woman's children died during the previous 36 months. We use the same lookback period as our conflict measure since we are interested in conflict-related child deaths. Our second pathway of interest is marriage, which we capture with a binary variable that differentiates between women who are and are not married. The former includes women who are formally married or cohabitating and the latter includes those who are single and never married, widowed, separated, or divorced. The third and final outcome is current modern contraceptive use, which is modeled as a binary variable. ${ }^{14}$ These three proposed mechanisms are not exhaustive, of course, but are theoretically relevant and observed across all rounds of the DHS included in our sample. We do not test the hypothesized sexual violence pathway due to data limitations, but discuss existing evidence on this issue below.

\section{Statistical Models}

We estimate a series of multivariate regression models to evaluate the respective relationships between exposure to conflict and both ideal and recent fertility. These models take the general form:

$$
\mathrm{Y}_{i(s)}=\alpha_{d}+\delta \mathrm{C}_{j p}+\beta \mathrm{X}_{i(s)}+\rho \mathrm{T}_{r}+\varepsilon_{i(s)}
$$

where the fertility outcome $\mathrm{Y}$ for woman $i$, drawn from sample $s$, is a function of conflict exposure $\mathrm{C}$, measured at the level of community $j$ over time period $p$, and a set of social and demographic control variables $X$. These control variables include the age of the respondent, an ordinal measure of educational attainment, the number of children ever born to the respondent, and a binary measure of whether the respondent lives in a rural or urban area. All models also include spatial

\footnotetext{
${ }^{14}$ Models of any contraceptive use (current or previous) yield similar results.
} 
$\left(\alpha_{d}\right)$ fixed effects and linear time trends (T) for each region $(r)$ of sub-Saharan Africa. The spatial fixed effects control for all time-invariant characteristics at the province level, defined as the first sub-national administrative unit for each country. The region-specific time terms control for common changes that occur linearly within each of the four major regions of sub-Saharan Africa defined by the United Nation Statistical Division. We cluster the standard errors on the DHS clusters $(n=18,880)$ and apply person-level survey weights throughout the analyses.

Within this overall framework, the models we estimate take multiple functional forms. We estimate linear regression models of the association between conflict and ideal family size; and estimate logistic regression models to evaluate the association between conflict and women's probability of giving birth in the past 12 months. We also estimate logistic regression models for our analysis of mechanisms since all three outcomes are binary. ${ }^{15}$ For each of the two main outcome variables, we test for variation in conflict effects across demographic groups of interest by including conflict-by-group interaction terms. These models allow for variation in the association between conflict and our two reproductive outcomes by women's educational attainment, parity, residence in rural or urban communities, and fertility context, as measured by the total fertility rate in women's country of residence at the time of enumeration. We also estimate comparable country-stratified models as an alternative approach to assessing heterogeneous effects across contexts. These findings are briefly discussed below, and the full results are presented in the Online Supplementary Information.

\section{Results}

\footnotetext{
${ }^{15}$ The number of children ever born is excluded as a control in the model of women's marital status. Although premarital childbearing is common and/or increasing in some parts of the region, a substantial majority of women still do not have a child before marriage (Clark et al. 2017) raising concerns about endogeneity.
} 


\section{Conflict and Fertility Ideals}

We begin by analyzing the association between exposure to armed conflict events and women's ideal family size (Table 2). In the first model (Model 1), we compare the preferred family size of women who were exposed to at least one conflict event during the 36 months prior to the survey with women living in areas that were conflict-free during the same time interval, controlling for a set of individual and household characteristics, time invariant province characteristics, and regionspecific time trends. The results reveal a negative association between conflict exposure and fertility ideals: conflict-affected women report ideal family sizes that are on average 0.05 -children lower than non-exposed women. This effect is just over 20 percent of the marginal difference in ideal family size associated with a one-child increase in parity $(\beta=0.241)$. The magnitude of this association suggests that, on average, conflict is a relatively limited source of cross-sectional variation in fertility ideals across sub-Saharan Africa. Given that ideal family size is a relatively "fuzzy" concept to begin with, even a one-child difference in the ideal family size of an individual woman may not represent a substantively meaningful change. On the other hand, it is important to recall that this figure represents an average across a large target population, such that small shifts in average preferences and probabilities may result in large aggregate changes across the population. It is also worth noting that this negative association runs contrary to the abovementioned upward bias potentially induced by selective out-migration from conflict-affected communities. Moreover, high-fertility contexts—for example demographic "youth bulges"-have generally been found to produce more rather than less conflict (e.g., Brunborg and Urdal 2005; Urdal 2006). That we find measures of conflict to reduce women's ideal family size runs counter to the expected relationship should the results be driven by reverse causation. 
(Table 2)

We next evaluate whether the association between conflict exposure and fertility ideals varies across demographic groups and contexts (Table 3), which we expect given hypothesized differences in populations' vulnerability and responses to conflict. We first test for differences by educational attainment (Model 2). Previous research suggests that better-educated women are more likely than others to perceive that their fertility is within their control (Behrman 2015) and may therefore be more likely to respond to the threat of violent conflict by modifying their desired family size (either upward or downward). On the other hand, better-educated women may have more resources to buffer the economic effects of conflict, making them less sensitive to these shocks (Zimmerman and Carter 2003). Consistent with the latter expectation, we find that conflict prompts only the least-educated women to reduce their desired family size, and that more-educated women experience statistically different—and near-zero — changes in ideal family size when exposed to conflict. Among women with no education, exposure to conflict events is associated with a reduction in ideal family size of 0.37 children - a substantively meaningful association when considered in the context of other coefficients—while the net conflict effects among women who completed some or all of primary school are both statistically non-significant at conventional thresholds $(\beta=-0.027, p=0.396$ and $\beta=0.044, p=0.073$, respectively).

\section{(Table 3)}

Next, we test for variation in armed-conflict effects by parity (Model 3), which may be expected given differential resource constraints between large and small families (Blake 1981; Smith-Greenaway and Trinitapoli 2014). Such variation may also be expected given women's differential likelihood of revising fertility goals across various stages of their reproductive careers (Bongaarts 1990; Casterline and El-Zeini 2007; Yeatman et al. 2013). We find that differences in 
conflict effects by parity are statistically and substantively significant. Women without children experience statistically significant increases in ideal family size when exposed to conflict, but this effect is moderated - and then reversed - as women's parity increases. As such, we observe increasingly large conflict-induced declines in ideal family size among women with large numbers of children. According to point estimates, for example, conflict exposure is associated with a $0.07-$ child decline in preferred family size among women with three children and a 0.25 -child decline among women with five children. The pattern of conflict effects across a broader range of parities is plotted in Panel A of Figure 2. A notable implication of these findings is that women with large families are more likely to revise their preferred family size downward in response to conflict. This finding runs counter to the possible influence of ex post rationalization on estimates, whereby women with higher numbers of children ever born are less likely to revise their fertility ideals to a lower level (Bongaarts 1990; Casterline and El-Zeini 2007). In contrast, we find the opposite and speculate that higher-parity women are more responsive to conflict exposure than others since they have experienced the unique burdens of having multiple children in conflict zones and may already be facing resource constraints. Such an explanation is consistent with the economic and risk mechanisms linking conflict and fertility.

The next model tests for differences between rural and urban areas, which may be expected given systematic differences in wealth, resilience, and reproductive norms between such contexts in Africa (Eloundou-Enyegue and Giroux 2012; Sahn and Stifel 2003). On the one hand, rural dwellers may be more isolated in terms of markets and infrastructure (e.g., travel and communications) than urban dwellers such that violence may have a more localized impact in rural areas. On the other, populations in urban areas are wealthier, have better security infrastructure, and may therefore be more resilient in the face of conflict and violence than rural populations. The 
implications of exposure to violence as measured here may also vary between urban and rural areas in a more technical sense: given differences in population density and distribution, individuals in rural areas may be more likely to be personally exposed to a violent event that occurs within a given radius than an urban resident. Our results provide only limited support for these expectations. There are not statistically significant differences in conflict effects between rural and urban populations, but we note that the point estimate of the net conflict effect is statistically significant for the rural population $(\beta=-0.088, \mathrm{p}=0.035)$ and not the urban population $(\beta=-0.019, \mathrm{p}=$ $0.504)$.

The fourth and final interaction model (Model 5) tests for differences in conflict effects across stages in the fertility transition, as indicated by the total fertility rate of women's country of residence at the time of enumeration. Such differences may be expected since perceptions of control over reproduction and related norms vary across the fertility transition and may thus affect women's ability and inclination to modify their fertility (Coale 1973; Hayford and Agadjanian 2011). Overall levels of fertility may also be correlated with perceptions of children as either a net benefit or cost to the household (Caldwell 1976), which is an important determinant of how women may respond to conflict-induced economic pressures. The results indicate that conflict effects vary systematically across the sample, with the strongest, negative effects occurring in high-fertility contexts. Here it is important to keep in mind the observed total fertility rates range from 3.3 to 7.2 across the sample (mean $=5.3$ ), with the corresponding marginal effects of conflict ranging from $\beta=0.116(p=0.061)$ to $\beta=-0.169(p=0.002)$ (Panel $B$, Figure 2). Across our target population, negative conflict effects are concentrated in the highest-fertility (and usually leastdeveloped) contexts while conflict has null effects in the lowest-fertility (and usually mostdeveloped) places. 
As an alternative means of examining contextual variation in conflict effects, we also estimate and report country-stratified models of ideal family size. We present this extensive set of results in the Online Supplementary Information (Table A4) but note that our findings show a nontrivial degree of heterogeneity across countries in the sample. While in most cases the effects of conflict are negative or not statistically significant, in three countries-Angola, Cameroon, and Rwanda —we observe conflict-related increases in ideal family size. The implication is that the estimates of our global model cannot be generalized across all countries in the sample.

(Figure 2)

\section{Conflict and Fertility Outcomes}

The second set of analyses examines the association between exposure to conflict and recent fertility outcomes, operationalized as the probability of having a child in the year prior to the survey. Following a similar sequence of models as our analysis of preferred family size, we first compare the conditional probability of recent fertility among women exposed to any conflict events in the prior 36 months with their non-exposed counterparts (Model 6, Table 4). We find that exposure to conflict is negatively associated with fertility: according to point estimates (odds ratio, $\mathrm{OR}=0.943$ ), conflict-exposed women were approximately 6 percent less likely to have a child in the 12 months prior to the survey than women residing in areas without armed conflict events over the previous three years. Holding control variables at their means, this estimated effect translates into an approximately 1.0 percentage point decline in the predicted annual probability of childbearing. When applied to our large target population, this relatively small change in probability may result in an absolutely large number of births that do not occur or are delayed. As with our model of ideal family size, we note that the negative effect of conflict on recent fertility 
that we observe runs counter to the conflict-increasing effect of high birth rates hypothesized by some scholars and to the potential upward bias from selective conflict-related out-migration (Brunborg and Urdal 2005; Urdal 2006). This pattern suggests that our estimates are unlikely to be driven by reverse causality or selection bias and, if anything, will be conservative.

(Table 4)

The next set of models test for variation in conflict effects across demographic groups of interest, motivated by a similar set of expectations as our models of fertility preferences above. We first examine differences in conflict effects by women's educational attainment (Model 7, Table 5). The results show that exposure to conflict is not significantly associated with changes in recent fertility among women with no education, but conflict effects are statistically different, and lower, among women with an incomplete or complete primary school education. The net effects of conflict exposure among these latter two groups are $\beta=-0.112(p=0.007)$ and $\beta=-0.079(p=$ 0.014), respectively. These results differ substantively from the models of ideal family size, which showed negative conflict effects concentrated among women without formal education.

The second interaction model (Model 8, Table 5) tests for differences in conflict effects by parity. Exposure to conflict is associated with reductions in fertility among women with few or zero children, but this association is offset and eventually reversed as parity increases. For example, conflict is associated with a 3.8 percent increase in the odds of recent fertility among women with 6 children (see Panel A, Figure 3). These findings would suggest that conflictinduced fertility declines among lower-parity women - who appear to increase their ideal family size when exposed to conflict - are in large part due to involuntary or indirect factors, such as delayed marriage, spousal separation, or malnutrition-related infecundity. We explore a number of these pathways in further analysis reported below. 
Third, we examine differences between rural and urban areas. Consistent with models of ideal family size, results show non-significant differences in conflict effects between rural and urban populations. However, the results also suggest that the effects of conflict are null or quite weak in urban areas $(\beta=-0.039, \mathrm{p}=0.269)$, whereas among rural populations we find a substantively and statistically significant negative association $(\beta=-0.076, \mathrm{p}=0.022)$. Exposure to conflict is associated with a nearly 8 percent reduction in rural women's odds of giving birth within the last year.

We next test for differences in conflict effects across stages of the fertility transition, as proxied by the national total fertility rate. In contrast to the model of ideal family size, we find no evidence of systematic variation in conflict effects on fertility according to the broader fertility context (Panel B, Figure 3). Finally, we again estimate country-stratified models as an alternative means of testing for heterogeneity across contexts (Table A5 in the Online Supplementary Information). We find no instances in which the direction of conflict effects differs from the main model (i.e., is positive), but for many countries the coefficient estimates are not statistically significant.

(Figure 3)

(Table 5)

\section{Mechanisms}

We further explore the above findings by analyzing the relationship between exposure to conflict and three outcomes that correspond to plausible pathways between conflict and changing reproductive goals and outcomes. The first of these models examines the relationship between conflict exposure and the probability that one or more of a women's children died during the same 
36-month period over which we measure conflict exposure (Model 11, Table 6). The results show a non-significant association between conflict and child deaths, which provides provisional evidence that most women exposed to conflict are not experiencing the child deaths that might spur a replacement effect. This finding is consistent with the results of the overall models of fertility goals and outcomes, which were negatively associated with conflict and thus contrary to what would be observed if replacement effects were strong.

The second model examines the relationship between exposure to conflict and women's marital status (Model 12, Table 6), differentiating between currently married and unmarried women. We find that conflict exposure is associated with a reduction in the odds that a woman was married at the time of the survey, and thus an increase in the odds that they have never married or are widowed, separated, or divorced. Point estimates suggest that conflict exposure is associated with an approximately 7.4 percent reduction in the odds of being married at the time of the survey. It is important to note that this decline in marriage may be driven by conflictrelated delays in marriage, union dissolution, spousal mortality, or some combination of these processes. Moreover, the negative association between conflict exposure and marriage is consistent with much of what we find above, most prominently the negative association between conflict exposure and observed fertility. Given that a majority of women have children within marriage in most (though not all) parts of sub-Saharan Africa (Clark et al. 2017, SmithGreenaway and Clark 2018), a delay or decline in fertility will result in fewer recent births. The negative association between conflict exposure and marriage also helps to explain the inconsistency in the direction of conflict effects on ideal family size (positive) and recent fertility (positive) among women without children. Such women are most likely to be single and never married, such that conflict-related delays in marriage would reduce their likelihood of recently having children despite increased ideal family size. 
Third and finally, we analyze the relationship between conflict exposure and current modern contraceptive use (Model 13, Table 6). We find no evidence of a relationship between recent exposure to armed conflict and the odds that a woman was using contraceptives at the time of the survey. This results suggests that conflict events we observe did not systematically affect contraceptive use. ${ }^{16}$ This result is consistent with our overall finding of a negative association between conflict and recent fertility since conflict-induced disruptions to contraceptive use would have led to an increase rather than decrease in births. Overall, then, this analysis of hypothesized mechanisms is consistent with results from the main models: it suggests that delays and declines in marriage may explain at least some of the conflict-induced reductions in reproductive goals and fertility.

(Table 6)

Robustness checks

In addition to examining potential causal mechanisms, we conducted a series of supplemental analyses to evaluate whether our substantive conclusions about the effects of conflict on fertility goals and outcomes were sensitive to key methodological decisions. In the two paragraphs below, we summarize the results of these tests for our analyses of ideal family size and recent fertility, respectively. We include a full set of results - including of other supplemental analyses - in the Online Supplementary Information.

Our finding that exposure to armed conflict is negatively associated with ideal family size is supported by a parallel logistic regression model predicting the desire for another child (Model

\footnotetext{
${ }^{16}$ We estimate an identical model of current contraceptive use limited to the sample of women who have not had a child within the past 12 months since those women are less likely to be using contraception because of ongoing breastfeeding (Model A5, Table A6). We also estimate a comparable model that predicts unmet need for family planning (Model A6, Table A7). We find no statistically significant conflict effects in either model.
} 
A7, Table A8), which suggests our findings are not driven by our choice among these related outcome variables. We then estimate a series of linear regression models of ideal family size (Table A9) among a sample restricted to women within ten years of their first marriage ${ }^{17}$ (Model A8), using an ordinal rather than binary measure of conflict exposure (Model A9), and measuring conflict exposure to also include nearby riots and violence against civilians (Model A10). These models yield results consistent with the main specification and suggest that exposure to multiple conflict events have particularly strong effects. Additional models of ideal family size employed binary measures of conflict exposure using alternative radii (50 kilometers and 100 kilometers, Models A11 and A12) and time periods (24 months and 48 months, Models A13 and A14) to measure conflict exposure, and all results are generally consistent with the main specification. The one exception is that the estimated coefficient on the conflict variable falls below conventional thresholds for statistical significance when measured over a 24-month lookback. Finally, we replicate our main specification using an alternative conflict dataset from the Uppsala Conflict Data Program (UCDP; Sundberg and Melander 2013) and results also show a negative association between armed conflict exposure and ideal family size (Model A15). The point estimate of this model is larger in absolute magnitude than our main results using ACLED, which suggests our estimates for this outcome may be conservative.

The second set of robustness checks largely parallel the abovementioned analysis but for models of recent fertility (Table A10). We first re-estimate our main specification using an ordinal measure of conflict exposure (Model A16). The point estimates of all conflict variables are negative, but only the indicator of exposure to one conflict event is statistically significant. We then employ a more expansive definition of conflict as described above (Model A17) and use

\footnotetext{
${ }^{17}$ Some analyses of fertility ideals have focused on this sub-population under the assumption such women's ideal family size is more dynamic and less prone to ex post rationalization (Bongaarts and Casterline 2013).
} 
alternative radii (50 kilometers and 100 kilometers, Models A18 and A19) and time periods (24 months and 48 months, Models A20 and A21) for measuring conflict exposure. The models using a 50-kilometer buffer and a 24-month lookback period to measure exposure both yield results that are consistent with the main findings, though the coefficient estimates are only marginally significant. The diminished precision is not necessarily surprising given that the larger spatial radius represents a conservative test of conflict effects, and that a 24 -month lookback period represents a short time window when modeling recent fertility given a 9-month gestational period. However, this logic is inconsistent with the null conflict effect when using a 48-month lookback period, which suggest one should interpret our findings from the main model with some caution. The models employing a broader definition of conflict and 100-kilometer radius for measuring conflict each find non-significant conflict effects, which is in line with our argument that proximate exposure to armed conflict (as distinct from other forms of unrest) is most important for determining reproductive outcomes. Finally, we again replicate our main specification using UCDP data (Model A22), but here the results suggest null conflict effects. This finding also suggests the need for some caution when interpreting the main estimates of conflict effects on fertility.

\section{Discussion and Conclusion}

In this study, we provide new evidence of how conflict has influenced reproductive goals and outcomes since the early 2000s across 25 sub-Saharan African countries. We build on prior work in this area by simultaneously 'zooming out' to produce estimates across and within a geographically and temporally broad population, and 'zooming in' to measure exposure to particular types of conflict events at a high spatial and temporal resolution. These localized 
measures better-correspond to the time periods and spaces in which conflict impacts are experienced, and thus affect fertility, than the coarse measures used in much of the existing literature.

Our approach yields results that significantly extend substantive knowledge about whether and how reproductive goals and outcomes are affected by conflict. We highlight three main conclusions. First, localized exposure to armed conflict is significantly associated with reductions in both preferred family size and the probability of recent childbearing among women in the populations we study. Conflict-exposed women have diminished reproductive goals, and may also have fewer children - at least in the short run. The correspondence between these two findings suggests that, on average, conflict-induced fertility declines may be driven by processes that are intentional (e.g., preventing pregnancies due to economic concerns) or that affect reproductive goals and behaviors simultaneously (e.g., changes in relationship status). However, it is important to note that the estimates of average conflict effects are modest in magnitude. Exposure to conflict influences reproductive goals and outcomes, but not dramatically when viewed across our entire population of interest. This conclusion highlights the need to also consider the other plausible ways that households may adapt to conflict (Williams 2013).

Second and relatedly, we find systematic variation in conflict effects between demographic groups and across contexts. The negative effects of conflict on ideal family size are concentrated among women with no education, at higher parities, and who reside in rural areas or countries early in the fertility transition. This set of findings is in line with a scenario in which the poorest are most vulnerable to conflict and relatedly, conflict-induced resource constraints push women to desire smaller families. Such changes in reproductive preferences are likely correlated with other coping behaviors and point to a need for targeting interventions to the most vulnerable sub- 
populations (Korf 2004). Models of recent childbearing show that conflict also reduces fertility among rural women. In contrast to the models of ideal family size, however, conflict is also associated with reductions in births among women who completed some or all of primary school and who were at lower parities. While declines in ideal family size are not necessarily contradictory to recent childbearing, these findings suggest that women without education or at high parities may have been unable to realize conflict-related changes in reproductive goals. The implication for policymakers is that unmet need for contraceptives, or a lack of empowerment to make reproductive decisions, may be exacerbated in conflict settings (McGinn et al. 2011).

Third, our parallel analysis of three plausible causal mechanisms show that conflict may lead to delays or a reduction in marriage, which is in line with a long historical record of demographic responses to unrest (Caldwell 2004). These changes are consistent with the overall negative associations between conflict and reproductive goals and outcomes that we observe. They may also explain corollary findings, such as the conflict-related decline in recent fertility among low-parity women—who are most likely to be unmarried. The policy responses to conflict-related delays or declines in marriage are not straightforward and will depend on the root cause of these changes (e.g., changing economic conditions, mobilization of men into armed groups). This finding nonetheless highlights the broader disruptions to social life caused by insecurity.

We find no significant associations between conflict exposure and either recent child deaths or contraceptive use, and therefore little evidence of replacement-effect and contraceptivedisruption pathways. These results are consistent with our overall findings since the latter two mechanisms would lead to increases rather than the observed decrease in fertility. Notably, we did not empirically assess whether conflict-related increases in sexual violence operated as a mechanism in our study since the requisite data were not available for a non-trivial share of our 
analytic sample. However, an analysis of many of the same DHS samples included in our study shows that conflict exposure increases women's risk of experiencing intimate partner sexual violence (Østby 2016). Read in parallel with our findings, this study suggests that conflict may also reduce reproductive goals and fertility by adversely affecting intra-household dynamics. With that said, Østby (2016) did not measure the effects of similar violent acts by combatants and other non-partners in conflict settings, which is an important topic for future research.

While many of our results are robust to a suite of alternative measurement and analytic decisions, the estimates of conflict effects on recent fertility were noticeably less consistent across sensitivity tests than our analysis of ideal family size. Conflict effects on recent childbearing may be weaker than on reproductive goals given heterogeneity in women's ability to realize the latter (Tsui et al. 2017; Wulifan et al. 2016). Further supplementary analysis suggests that the relationship between conflict and recent childbearing is robust among the sub-populations in which conflict effects were initially strongest. Readers should nonetheless draw conclusions about conflict and childbearing cautiously, and this relationship should be further examined in future research. Our results support the conclusion that conflict disrupts reproduction, but in a manner that will not manifest as "baby booms" or "baby busts."

Indeed, our findings and limitations therein raise multiple avenues for additional work on this topic. For one, while we examined variation in conflict effects across major sub-populations of interest, the harmonized data and methods we employ are well-suited to examine other socioeconomic and contextual modifiers of conflict effects. Examples include access to contraceptives, gender inequality, and the historical frequency of conflict (e.g., chronically insecure vs. recent outbreaks of violence). The heterogeneous results of our country-specific models in particular suggest attention to macro-level modifiers is merited. By employing our 
harmonized approach to such questions rather than comparing results of case studies, researchers can be confident that observed cross-national differences (or similarities) reflect substantive moderating processes and not methodological artifacts.

Future research should also work to further explore the causal pathways from conflict exposure to reproductive goals and outcomes. While our analysis of the relationship between conflict and plausible causal pathways provided valuable evidence to interpret our main findings, they were nonetheless limited by the cross-sectional nature of the DHS and the limited socioeconomic data collected in those surveys. Unpacking mechanisms will in part require the use of rich longitudinal datasets, which allow for the establishment of proper time order of mediation processes and that include detailed information on household social and economic conditions over time. Other novel datasets may also be valuable in this regard. For example, the Sexual Violence in Armed Conflict (SVAC) dataset (Cohen and Nordås 2014) may help demographers understand the effects of conflict-related sexual violence on reproductive outcomes, which we could not empirically study here.

Additional work is also needed to explore the temporal dimensions of fertility responses to conflict, such as whether conflict-induced fertility declines are persistent or followed by postconflict rebounds among affected individuals (Lindstrom and Berhanu 1999; Agadjanian and Prata 2002; Agadjanian et al. 2011). Decomposing the quantum and tempo effects of conflict on fertility can enhance knowledge of the processes that explain this relationship and improve estimates of the demographic consequences of conflict over the long run. Panel data are again best suited for such analysis, but the DHS retrospective birth records can also be leveraged for these purposes. These and other extensions of the literature can significantly advance knowledge of how conflict and similar shocks affect human population dynamics. Given the persistently high levels of 
conflict across sub-Saharan Africa and other regions of the developing world, continued attention to the second-order consequences of violence will remain necessary to fully understand the impacts of insecurity, and to enhance policymakers' and practitioners' ability to assist conflict-affected populations. 


\section{References}

Adhikari, P. (2012). Conflict-induced Displacement, Understanding the Causes of Flight. American Journal of Political Science, 57(1), 82-89.

Agadjanian, V. \& Prata, N. (2002). War, Peace, and Fertility in Angola. Demography, $39(2), 215-31$.

Agadjanian, V., Yabiku, T., \& Boaventura, C. (2011). Men’s Migration and Women's Fertility in Rural Mozambique. Demography, 48(3), 1029-48.

Akresh, R., Lucchetti, L., \& Thirumurthy, H. (2012). Wars and Child Health: Evidence from the Eritrean-Ethiopian Conflict. Journal of Development Economics, 99(2), 330-340.

Armed Conflict Location and Event Database (ACLED). Available online at: https://www.acleddata.com/data/. Accessed 11 June 2019.

Behrman, J. A. (2015). Does Schooling Affect Women's Desired Fertility? Evidence from Malawi, Uganda, and Ethiopia. Demography, 52(3), 787-809.

Berrebi, C. \& Ostwald, J. (2015). Terrorism and Fertility: Evidence for a Causal influence of Terrorism on Fertility. Oxford Economic Papers, 67(1), 63-82.

Blake, J. (1981). Family Size and the Quality of Children. Demography, 18(4), 421-442.

Blanc, A. (2004). The Role of Conflict in the Rapid Fertility Decline in Eritrea and Prospects for the Future. Studies in Family Planning, 35(4), 236-45.

Bohra-Mishra, P. \& Massey, D. S. (2011). Individual Decisions to Migrate During Civil Conflict. Demography, 48(2), 401-424.

Bongaarts, J. (1990). The Measurement of Unwanted Fertility. Population and Development Review, 16(3), 487-506. 
Bongaarts, J. (2001). Fertility and Reproductive Preferences in Post-Transitional Societies. Population and Development Review, 27, 260-281.

Bongaarts, J. \& Casterline, J. (2013). Fertility Transition: Is Sub-Saharan Africa Different? Population and Development Review, 38, 153-168.

Boyle, E., King, M., \& Sobek, M. (2018). IPUMS-Demographic and Health Surveys: Version 5. IPUMS and ICF international, 2018.

Brunborg, H. \& Urdal, H. (2005). The Demography of Conflict and Violence: An Introduction. Journal of Peace Research, 42(4), 371-374.

Buhaug, H. \& Rød, J. (2006). Local Determinants of African Civil Wars, 1970-2001. Political Geography, 25(3), 315-335.

Burgert, C. R., Colston, J., Roy, T., \& Zachary, B. (2013). Geographic Displacement Procedure and Georeferenced Data Release Policy for the Demographic and Health Surveys.

Caldwell, J. C. (1976). Toward a Restatement of Demographic Transition Theory. Population and Development Review, 2(3/4)_321-366.

Caldwell, J. C. (2004). Social Upheaval and Fertility Decline. Journal of Family History, 29(4), 384-406.

Casterline, J. B. \& El-Zeini, L. O. (2007). The Estimation of Unwanted Fertility. Demography, 44(4), 729-745.

Cetorelli, V. (2014). The Effect on Fertility of the 2003-2011 War in Iraq. Population and Development Review, 40(4), 581-604.

Chi, P. C., Bulage, P., Urdal, H., \& Sundby, J. (2015). Perceptions of the Effects of Armed Conflict on Maternal and Reproductive Health Services and Outcomes in Burundi and 
Northern Uganda: A Qualitative Study. BMC international Health and Human Rights, $15(1), 7$.

Clark, S., Koski, A., \& Smith-Greenaway, E. (2017). Recent Trends in Premarital Fertility Across Sub-Saharan Africa. Studies in Family Planning, 48(1), 3-22.

Coale, A. (1973) “The Demographic Transition Reconsidered”. Pp. 53-72 in International Population Conference, Vol. 1. International Union for the Scientific Study of Population, Liege.

Cohen, D. K., \& Nordås, R. (2014). Sexual Violence in Armed Conflict: Introducing the SVAC Dataset, 1989-2009. Journal of Peace Research, 51(3), 418-428.

Collier, P., Elliot, V. L., Hegre, H., Hoeffler, A., Reynal-Querol, M., \& Sambanis, N. (2003). Breaking the Conflict Trap: Civil War and Development Policy. World Bank Policy Research Report \#26121.

Corno, L., Hildebrandt, N., \& Voena, A. (2017). Age of Marriage, Weather Shocks, and the Direction of Marriage Payments. National Bureau of Economic Research Working Paper 23604.

Czaika, M. \& Kis-Katos, K. (2009). Civil Conflict and Displacement: Village-Level Determinants of Forced Migration in Aceh. Journal of Peace Research, 46(3), 399-418.

Dabalen, A. \& Paul, S. (2014). Estimating the Effects of Conflict on Education in Côte d'Ivoire. The Journal of Development Studies, 50(12), 1631-46.

Dossa, N. I., Zunzunegui, M. V., Hatem, M., \& Fraser, W. (2014). Fistula and Other Adverse Reproductive Health Outcomes Among Women Victims of Conflict-Related Sexual Violence: A Population-Based Cross-Sectional Study. Birth, 41(1), 5-13. 
Eck, K. (2012). In Data We Trust? A Comparison of UCDP GED and ACLED Conflict Events Datasets. Cooperation and Conflict, 47(1), 124-141.

Eloundou-Enyegue, P. M. \& Giroux, S. C. (2012). Demographic Change and Rural-Urban Inequality in Sub-Saharan Africa: Theory and Trends. In International Handbook of Rural Demography (pp. 125-135). Springer, Dordrecht.

Frye, M. \& Bachan, L. (2017). The Demography of Words: The Global Decline in Non-Numeric Fertility Preferences, 1993-2011. Population Studies, 71(2), 187-209.

Gerland, P., Raftery A., Ševčíková H., Danan Gu, H., Spoorenberg, T., \& Alkema, L. (2014). World Population Stabilization: Unlikely This Century. Science, 346(6206), 234-237.

Ghobarah, H., Huth, P., \& Russett, B. (2003). Civil Wars Kill and Maim People—Long after the Shooting Stops. American Political Science Review, 97(2), 189-202.

Hagan, J., Rymond-Richmond, W., \& Palloni, A. (2009). Racial Targeting of Sexual Violence in Darfur. American Journal of Public Health, 99(8), 1386-1392.

Hayford, S. R. \& Agadjanian, V. (2011). Uncertain Future, Non-Numeric Preferences, and the Fertility Transition: A Case Study of Rural Mozambique. African Population Studies, 25(2), 419 .

Hossain, M., Phillips, J. F., \& Legrand, T. K. (2007). The Impact of Childhood Mortality on Fertility in Six Rural Thanas of Bangladesh. Demography, 44(4), 771-784.

Human Rights Watch. (2008). Collective Punishment: War Crimes and Crimes Against Humanity in the Ogaden Area of Ethiopia's Somali Regional State. New York, NY: Human Rights Watch. 
Islam, A., Ouch, C., Smyth, R., \& Choon Wang, L. (2015). The Long-Term Effects of Civil Conflicts on Education, Earnings, and Fertility: Evidence from Cambodia. Journal of Comparative Economics., 44(3), 800-820.

Korf, B. (2004). War, Livelihoods and Vulnerability in Sri Lanka. Development and Change, 35(2), 275-295.

Kraehnert, K., Brück, T., Di Maio, M., \& Nisticò, R. (2019). The effects of conflict on fertility: Evidence from the genocide in Rwanda. Demography. 1-34, forthcoming.

Lindskog, E. (2016). Effects of Violent Conflict on Women and Children: Sexual Behavior, Fertility, and Infant Mortality in Rwanda and the Democratic Republic of Congo. PhD Thesis, Stockholm University, Department of Sociology.

Lindstrom, D.P. \& Berhanu, B. (1999). The Impact of War, Famine, and Economic Decline on Marital Fertility in Ethiopia. Demography, 36(2), 247.

Lindstrom, D. P. \& Kiros, G.-E. (2007). The Impact of Infant and Child Death on Subsequent Fertility in Ethiopia. Population Research and Policy Review, 26(1), 31-49.

McGinn, T. (2000). Reproductive Health of War-Affected Populations: What Do We Know? International Family Planning Perspectives, 26(4), 174-180.

McGinn, T., Austin, J., Anfinson, K., Amsalu, R., Casey, S. E., Fadulalmula, S., \& Yetter, M. (2011). Family Planning in Conflict: Results of Cross-Sectional Baseline Surveys in Three African Countries. Conflict and Health, 5(1), 11. H

Minoiu, C., \& Shemyakina, O. (2012). Child Health and Conflict in Côte d'Ivoire. American Economic Review, 102(3), 294-99.

Nobles, J., Frankenberg, E., \& Thomas, D. (2015). The Effects of Mortality on Fertility: Population Dynamics after a Natural Disaster. Demography, 52(1), 15-38. 
Olsen, R. (1980). Estimating the Effect of Child Mortality on the Number of Births. Demography, 17(4), 429-443.

Østby, G. (2016). Violence Begets Violence: Armed Conflict and Domestic Sexual Violence in Sub-Saharan Africa. Paper presented at the Workshop on Sexual Violence and Armed Conflict, New Research Frontiers, Harvard University. 2-3 September.

Østby, G., Urdal, H., Tollefsen, A. F., Kotsadam, A., Belbo, R., \& Ormhaug, C. (2018). Organized Violence and Institutional Child Delivery: Micro-Level Evidence from Sub-Saharan Africa, 1989-2014. Demography, 55(4), 1295-1316.

Pallitto, C. C., \& O'Campo, P. (2004). The Relationship between Intimate Partner Violence and Unintended Pregnancy: Analysis of a National Sample from Colombia. International Family Planning Perspectives, 30(4), 165-173.

Palmer, J. J. \& Storeng, K. T. (2016). Building the Nation's Body: The Contested Role of Abortion and Family Planning in Post-War South Sudan. Social Science \& Medicine, 168, 84-92.

Peterman, A., Palermo, T., \& Bredenkamp, C. (2011). Estimates and Determinants of Sexual Violence Against Women in the Democratic Republic of Congo. American Journal of Public Health, 101(6), 1060-1067.

Raleigh, C., Linke, A., Hegre, H., \& Karlsen, J. (2010). Introducing ACLED: An Armed Conflict Location and Event Dataset: Special Data Feature. Journal of Peace Research, 47(5), 651660.

Sahn, D. E. \& Stifel, D. C. (2003). Urban-Rural Inequality in Living Standards in Africa. Journal of African Economies, 12(4), 564-597.

Schindler, K. \& Brück, T. (2011). The Effects of Conflict on Fertility in Rwanda. World Bank Washington, DC. 
Smith-Greenaway, E. \& Trinitapoli, J. (2014). Polygynous Contexts, Family Structure, and Infant Mortality in Sub-Saharan Africa. Demography, 51(2), 341-366.

Smith-Greenaway, E., \& Clark, S. (2018). Women's Marriage Behavior Following a Premarital Birth in Sub-Saharan Africa. Journal of Marriage and Family, 80(1), 256-270.

Sundberg, R. \& Melander, E. (2013). Introducing the UCDP Georeferenced Event Dataset. Journal of Peace Research, 50(4), 523-532.

Torche, F. \& Shwed, U. (2015). The Hidden Costs of War: Exposure to Armed Conflict and Birth Outcomes. Sociological Science, 2(27), 558-581.

Torres, A. F. C. \& Urdinola B. Piedad (2009). Armed Conflict and Fertility in Colombia, 20002010. Population Research and Policy Review, 38(2), 173-213.

Tsui, A. O., Brown, W., \& Li, Q. (2017). Contraceptive practice in sub-Saharan Africa. Population and Development Review, 43(S1), 166-191.

Urdal, H. (2006). A Clash of Generations? Youth Bulges and Political Violence. International Studies Quarterly, 50(3), 607-629.

Urdal, H. \& Che, C. P. (2013). War and Gender inequalities in Health: The Impact of Armed Conflict on Fertility and Maternal Mortality. International Interactions, 39(4), 489-510.

Verwimp, P. \& van Bavel P (2005). Child Survival and Fertility of Refugees in Rwanda. European Journal of Population 21(2-3), 271-290.

Williams, N. E. (2013). How community organizations moderate the effect of armed conflict on migration in Nepal. Population Studies, 67(3), 353-369.

Williams, N.E. (2015). Mixed and Complex Mixed Migration During Armed Conflict: Multidimensional Empirical Evidence from Nepal. International Journal of Sociology, 45(1), 44-63. 
Williams, N. E., Ghimire, D. J., Axinn, W. G., Jennings, E. A., \& Pradhan, M. S. (2012). A Micro-Level Event-Centered Approach to Investigating Armed Conflict and Population Responses. Demography, 49(4), 1521-1546.

Williams, P. D. (2017). Continuity and Change in War and Conflict in Africa. Prism, 6(4), 3245.

Woldemicael, G. (2008). Recent Fertility Decline in Eritrea: Is it a Conflict-Led Transition? Demographic Research, 18(2), 27-58.

Woldemicael, G. (2010). Declining Fertility in Eritrea Since the Mid-1990s: A Demographic Response to Military Conflict. International Journal of Conflict and Violence, 4(1), 150. Wood, E. J. (2014). Conflict-Related Sexual Violence and the Policy Implications of Recent Research. International Review of the Red Cross, 96(894), 457-478.

World Bank. (2011). World Development Report 2011. Washington, DC: World Bank Group.

World Bank. (2018). World Governance Indicators. Washington, DC: World Bank Group.

Wulifan, J. K., Brenner, S., Jahn, A., \& De Allegri, M. (2016). A Scoping Review on Determinants of Unmet Need for Family Planning Among Women of Reproductive Age in Low and Middle Income Countries. BMC Women's Health, 16(1), 2.

Yeatman, S., Sennott, C., \& Culpepper, S. (2013). Young Women's Dynamic Family Size Preferences in the Context of Transitioning Fertility. Demography, 50(5), 1715-1737.

Zimmerman, F. J. \& Carter, M. R. (2003). Asset Smoothing, Consumption Smoothing and the Reproduction of Inequality Under Risk and Subsistence Constraints. Journal of Development Economics, 71(2), 233-260. 
Tables 
Table 1 Description of sample

\begin{tabular}{|c|c|c|}
\hline Variable & Mean & $\mathrm{SD}$ \\
\hline Ideal family size & 4.77 & 2.51 \\
\hline Birth in prior year (yes) & 0.173 & - \\
\hline Conflict (yes) & 0.131 & - \\
\hline Age (years) & 28.77 & 9.54 \\
\hline \multicolumn{3}{|l|}{ Education } \\
\hline None & 0.313 & - \\
\hline Incomplete primary school & 0.288 & - \\
\hline Complete primary school & 0.400 & - \\
\hline Children ever born & 3.03 & 2.84 \\
\hline \multicolumn{3}{|l|}{ Type of residence } \\
\hline Urban & 0.288 & - \\
\hline Rural & 0.712 & - \\
\hline \multicolumn{3}{|l|}{ Period } \\
\hline 2000-2006 & 0.383 & - \\
\hline 2006-2011 & 0.334 & - \\
\hline 2012-2017 & 0.283 & - \\
\hline \multicolumn{3}{|l|}{ Region } \\
\hline Southern & 0.074 & - \\
\hline Eastern & 0.582 & - \\
\hline Western & 0.265 & - \\
\hline Central & 0.079 & - \\
\hline Sample size & & 368,765 \\
\hline
\end{tabular}

Estimates are calculated using DHS person weights. Distribution by period and region shown for informative purposes only; regression models control for province fixed effects and region-specific linear time trends. $\mathrm{TFR}=$ total fertility rate 
Table 2 Linear regression models predicting ideal family size

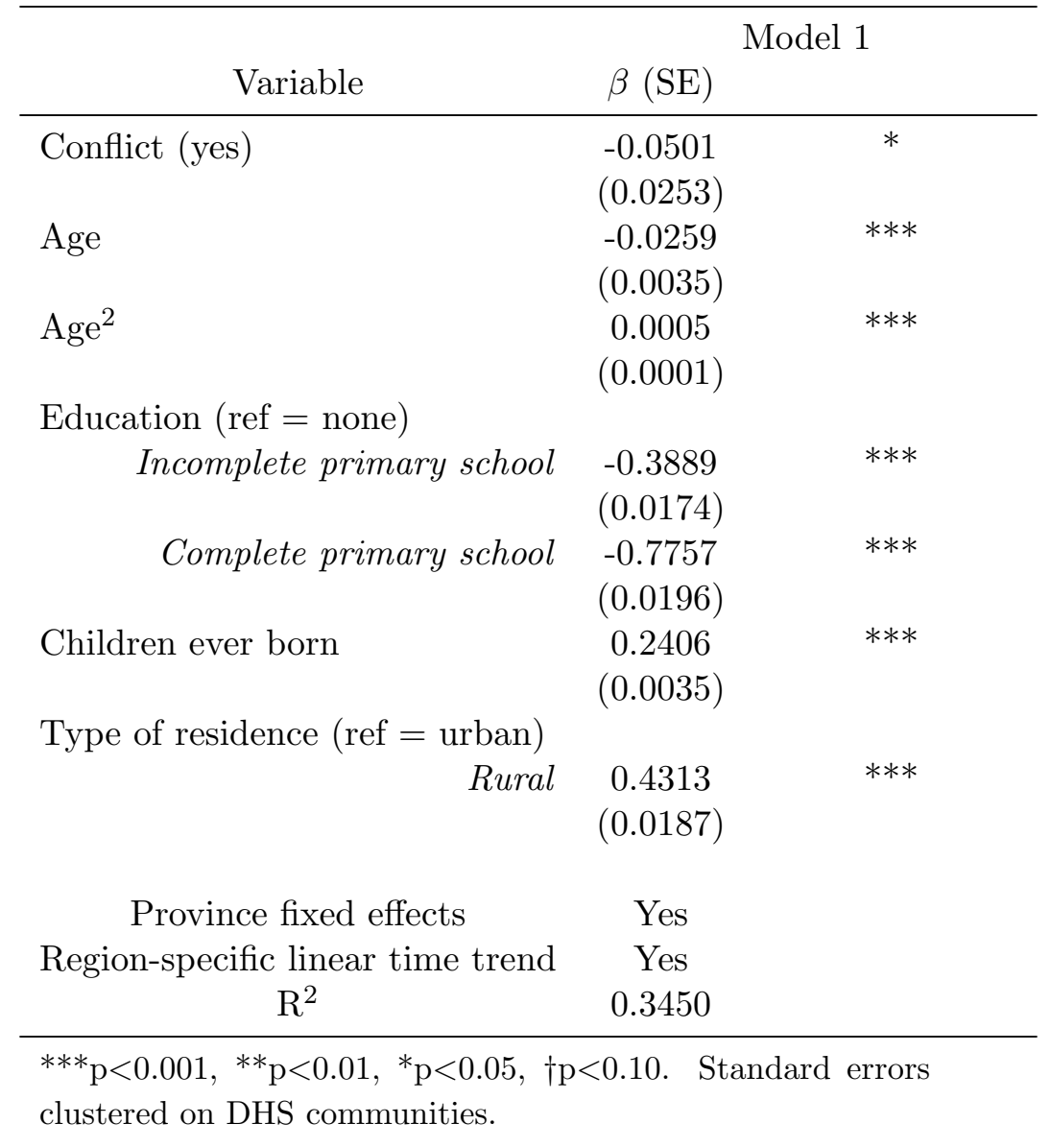




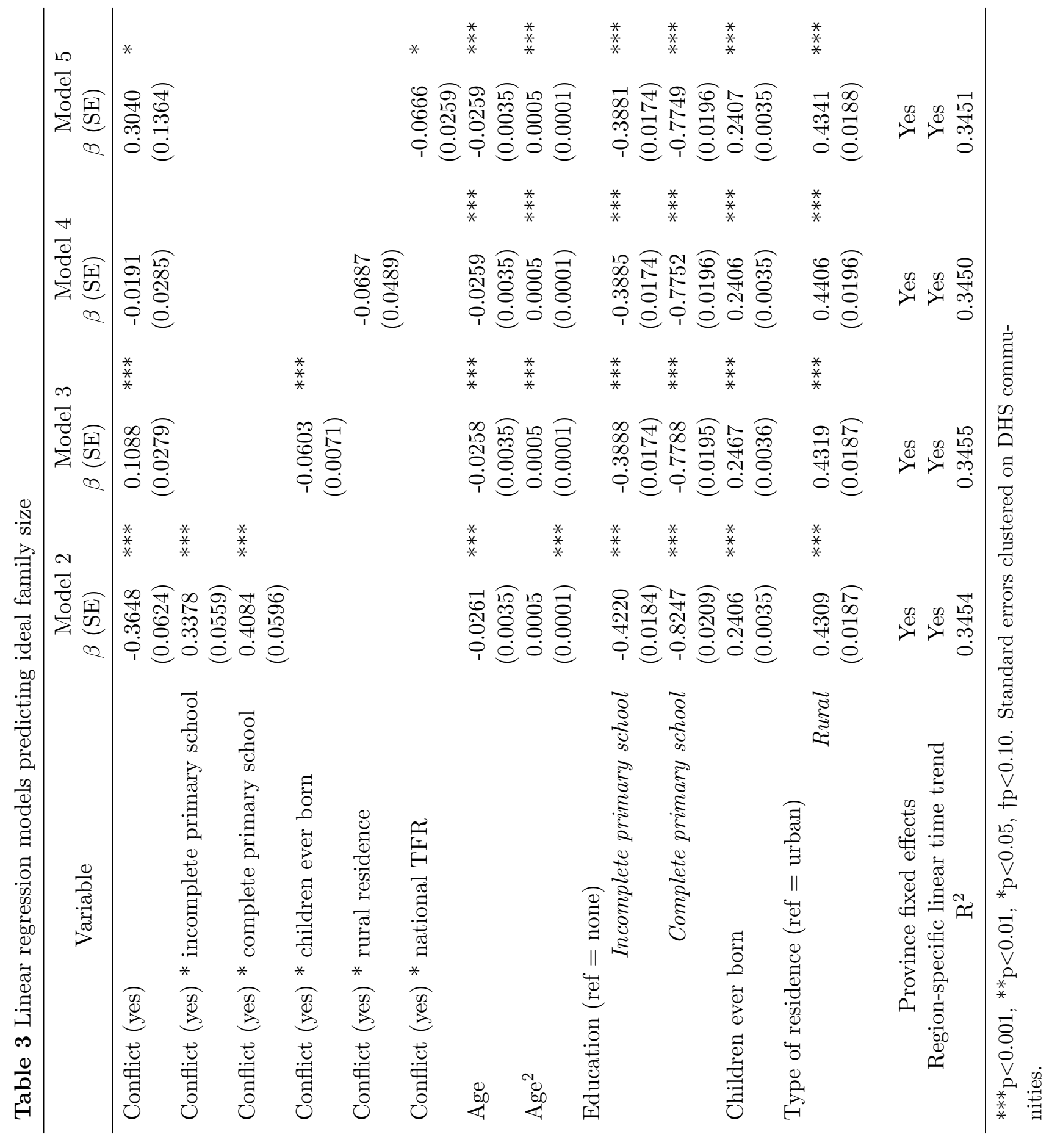


Table 4 Logistic regression models predicting any birth in prior year

\begin{tabular}{|c|c|c|}
\hline Variable & $\begin{array}{r}\text { Mod } \\
\beta(\mathrm{SE})\end{array}$ & \\
\hline Conflict (yes) & $\begin{array}{l}-0.0582 \\
(0.0250)\end{array}$ & $*$ \\
\hline Age & $\begin{array}{c}0.3783 \\
(0.0057)\end{array}$ & $* * *$ \\
\hline $\mathrm{Age}^{2}$ & $\begin{array}{l}-0.0091 \\
(0.0001)\end{array}$ & $* * *$ \\
\hline \multicolumn{3}{|l|}{ Education $($ ref $=$ none $)$} \\
\hline Incomplete primary school & $\begin{array}{l}-0.0827 \\
(0.0178)\end{array}$ & $* * *$ \\
\hline Complete primary school & $\begin{array}{l}-0.0872 \\
(0.0186)\end{array}$ & $* * *$ \\
\hline Children ever born & $\begin{array}{c}0.4821 \\
(0.0047)\end{array}$ & $* * *$ \\
\hline $\begin{array}{r}\text { Type of residence }(\text { ref }=\text { urban }) \\
\text { Rural }\end{array}$ & $\begin{array}{c}0.1538 \\
(0.0177)\end{array}$ & $* * *$ \\
\hline $\begin{array}{c}\text { Province fixed effects } \\
\text { Region-specific linear time trend } \\
\text { Pseudo } \mathrm{R}^{2}\end{array}$ & $\begin{array}{c}\text { Yes } \\
\text { Yes } \\
0.1537\end{array}$ & \\
\hline
\end{tabular}




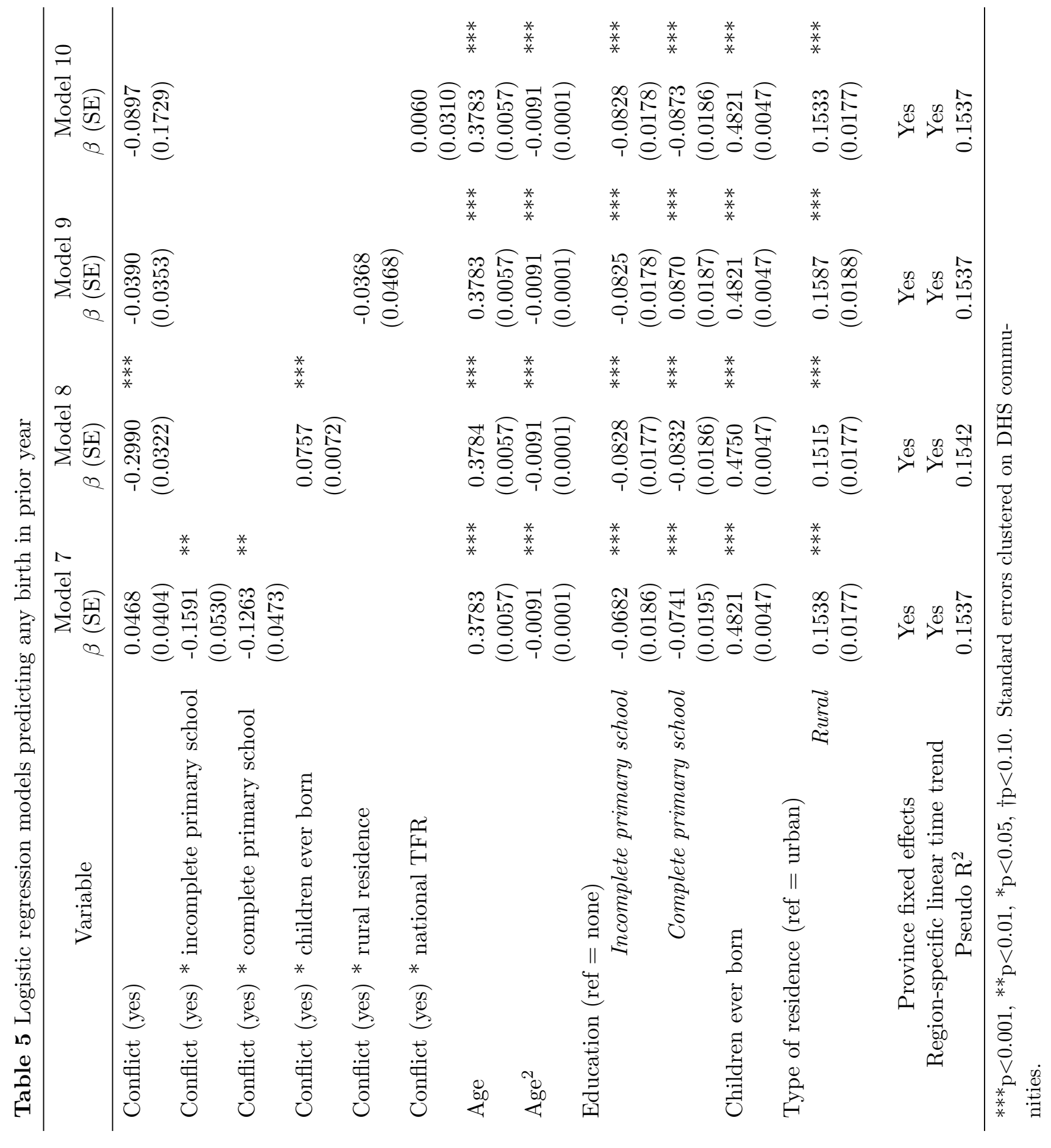


Table 6 Logistic regression models predicting child deaths, marital status, and contraceptive use

\begin{tabular}{|c|c|c|c|c|c|c|}
\hline Variable & $\begin{array}{l}\text { Model } \\
\text { Child } \\
\text { death }\end{array}$ & & $\begin{array}{l}\text { Model } 12 \\
\text { Married }\end{array}$ & & $\begin{array}{l}\quad \text { Model } \\
\text { Current } \\
\text { contra- } \\
\text { ception } \\
\text { use } \\
\beta(\mathrm{SE})\end{array}$ & \\
\hline Conflict (yes) & $\begin{array}{l}-0.0324 \\
(0.0412)\end{array}$ & & $\begin{array}{c}-0.0764 \\
(0.0254)\end{array}$ & $* *$ & $\begin{array}{l}-0.0097 \\
(0.0277)\end{array}$ & \\
\hline Age & $\begin{array}{c}0.1552 \\
(0.0070)\end{array}$ & $* * *$ & $\begin{array}{c}0.7319 \\
(0.0042)\end{array}$ & $* * *$ & $\begin{array}{c}0.3722 \\
(0.0047)\end{array}$ & $* * *$ \\
\hline $\operatorname{Age}^{2}$ & $\begin{array}{l}-0.0034 \\
(0.0001)\end{array}$ & $* * *$ & $\begin{array}{l}-0.0103 \\
(0.0001)\end{array}$ & $* * *$ & $\begin{array}{c}-0.0059 \\
(0.0001)\end{array}$ & $* * *$ \\
\hline \multicolumn{7}{|l|}{ Education (ref = none) } \\
\hline Incomplete primary school & $\begin{array}{c}-0.0724 \\
(0.0258)\end{array}$ & $* *$ & $\begin{array}{c}-0.3504 \\
(0.0191)\end{array}$ & $* * *$ & $\begin{array}{c}0.5462 \\
(0.0193)\end{array}$ & $* * *$ \\
\hline Complete primary school & $\begin{array}{l}-0.3554 \\
(0.0301)\end{array}$ & $* * *$ & $\begin{array}{l}-0.8217 \\
(0.0199)\end{array}$ & $* * *$ & $\begin{array}{c}0.8448 \\
(0.0215)\end{array}$ & $* * *$ \\
\hline Children ever born & $\begin{array}{c}0.3086 \\
(0.0051)\end{array}$ & $* * *$ & (excluded) & & $\begin{array}{c}0.1497 \\
(0.0034)\end{array}$ & $* * *$ \\
\hline $\begin{array}{r}\text { Type of residence }(\mathrm{ref}=\text { urban }) \\
\text { Rural }\end{array}$ & $\begin{array}{c}0.1980 \\
(0.0285)\end{array}$ & $* * *$ & $\begin{array}{c}0.4725 \\
(0.0183)\end{array}$ & $* * *$ & $\begin{array}{l}-0.4396 \\
(0.0199)\end{array}$ & $* * *$ \\
\hline $\begin{array}{c}\text { Province fixed effects } \\
\text { Region-specific linear time trend } \\
\text { Pseudo } \mathrm{R}^{2}\end{array}$ & $\begin{array}{c}\text { Yes } \\
\text { Yes } \\
0.1027\end{array}$ & & $\begin{array}{c}\text { Yes } \\
\text { Yes } \\
0.2934\end{array}$ & & $\begin{array}{c}\text { Yes } \\
\text { Yes } \\
0.1784\end{array}$ & \\
\hline
\end{tabular}

${ }^{* * *} \mathrm{p}<0.001,{ }^{* *} \mathrm{p}<0.01,{ }^{*} \mathrm{p}<0.05, \dagger \mathrm{p}<0.10$. Standard errors clustered on DHS communities. Contraceptive use defined to include only modern methods. 
Figures 


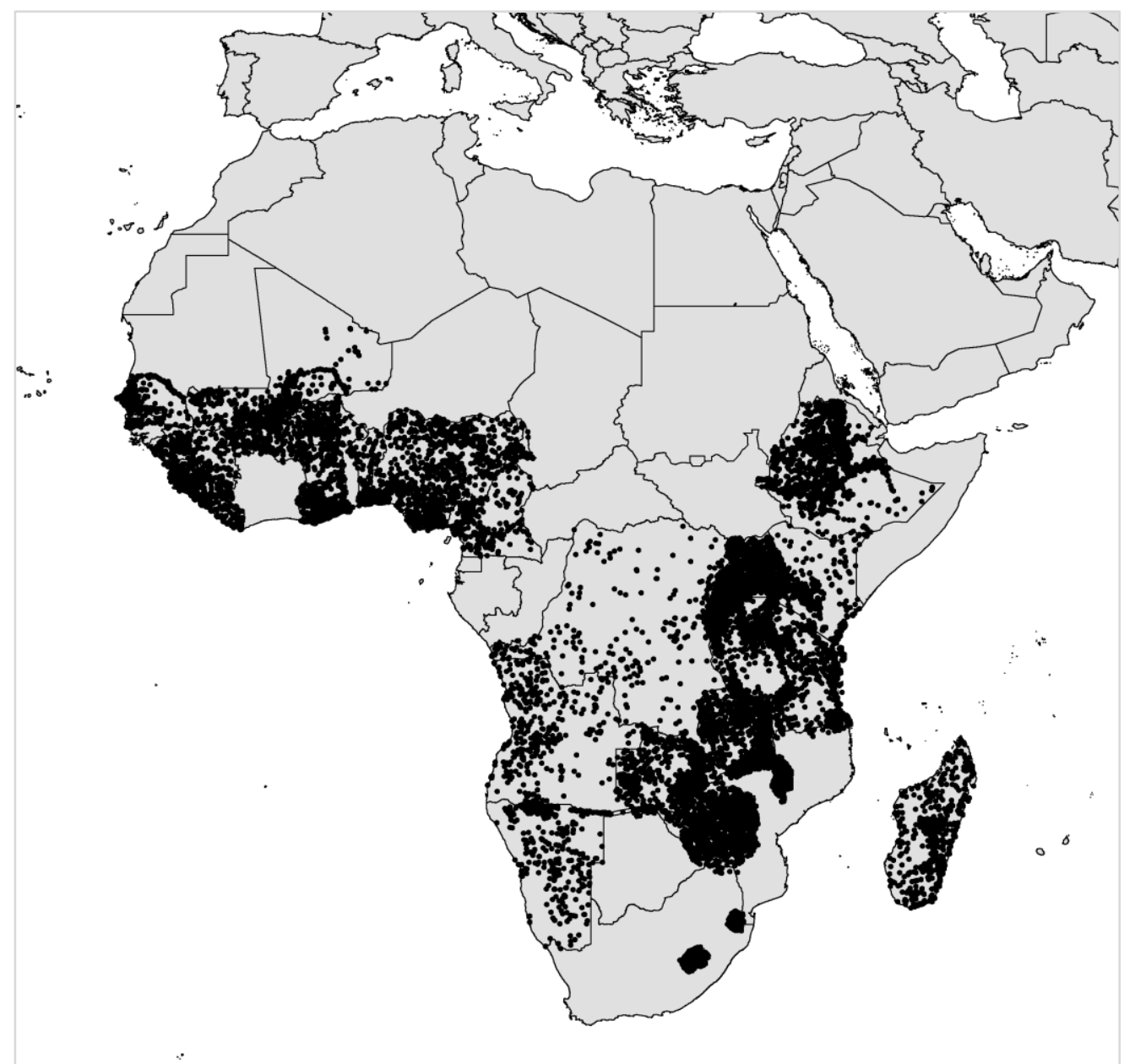

Figure 1 Map of DHS cluster locations in the analytic sample 


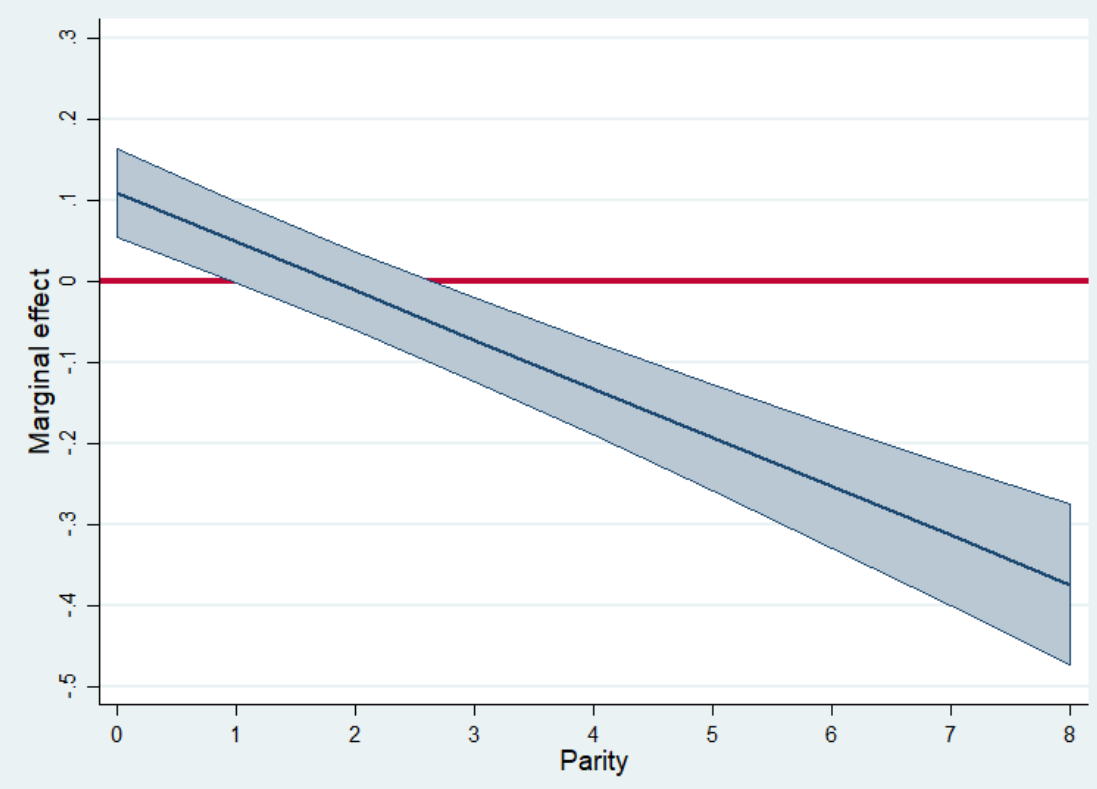

Panel A

Figure 2 Marginal effects of conflict on ideal family size, by parity (panel A) and total fertility rate of women's country of residence (panel B)

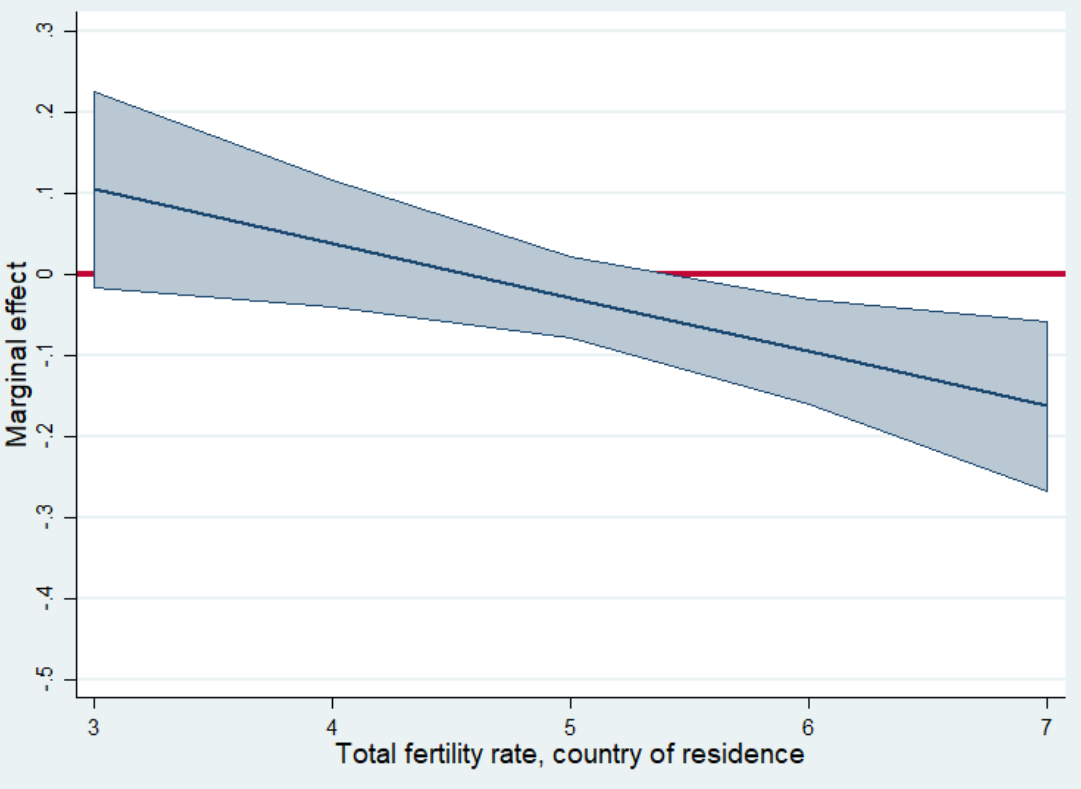

Panel B 

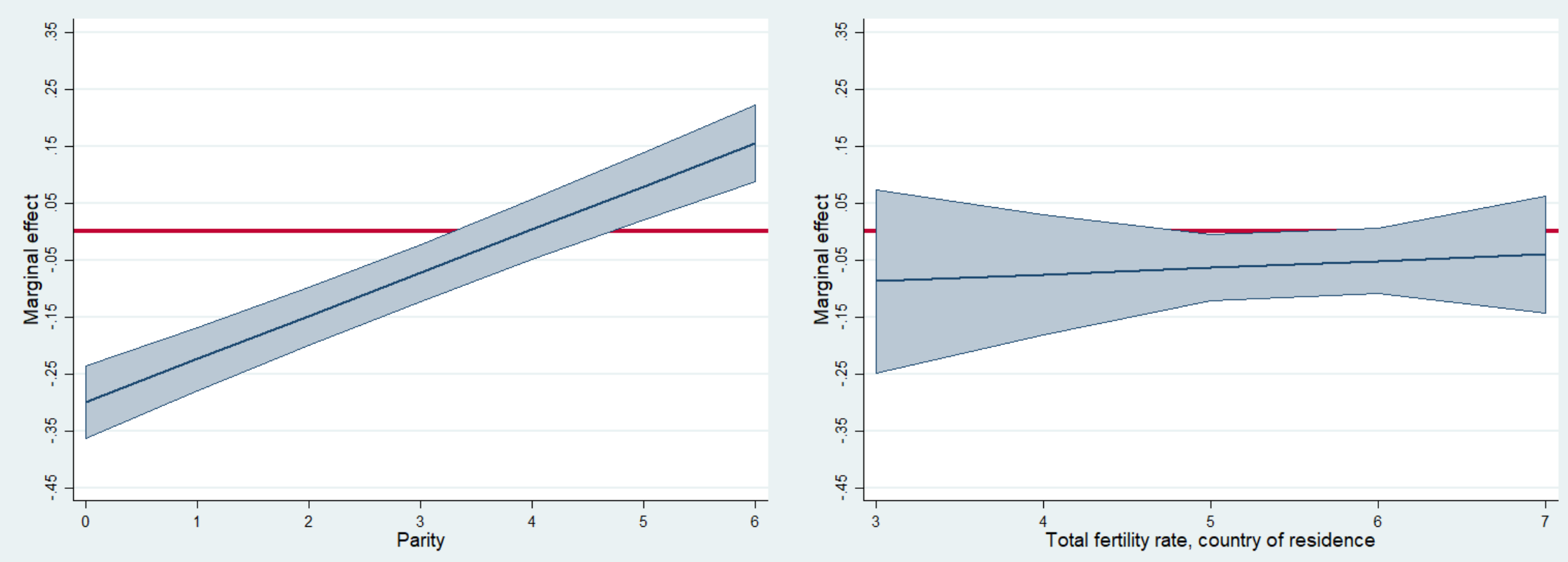

Panel A

Panel B

Figure 3 Marginal effects of conflict on childbearing in prior 12 months, by parity (panel A) and total fertility rate of women's country of residence (panel B) 
Online Supplementary Information 
Table A1 Distribution of sample and conflict exposure by country

\begin{tabular}{|c|c|c|}
\hline Country & $\begin{array}{l}\text { Proportion of } \\
\text { sample }\end{array}$ & $\begin{array}{l}\text { Proportion } \\
\text { exposed to } \\
\text { conflict }\end{array}$ \\
\hline Angola & 0.037 & 0.010 \\
\hline Benin & 0.012 & 0.000 \\
\hline Burkina Faso & 0.028 & 0.000 \\
\hline Burundi & 0.041 & 0.735 \\
\hline Cameroon & 0.019 & 0.006 \\
\hline Dem. Rep. Congo & 0.022 & 0.292 \\
\hline Eswatini & 0.010 & 0.202 \\
\hline Ethiopia & 0.096 & 0.101 \\
\hline Ghana & 0.022 & 0.085 \\
\hline Guinea & 0.017 & 0.098 \\
\hline Kenya & 0.033 & 0.300 \\
\hline Lesotho & 0.030 & 0.153 \\
\hline Liberia & 0.014 & 0.334 \\
\hline Madagascar & 0.039 & 0.112 \\
\hline Malawi & 0.155 & 0.029 \\
\hline Mali & 0.052 & 0.008 \\
\hline Namibia & 0.034 & 0.031 \\
\hline Nigeria & 0.077 & 0.190 \\
\hline Rwanda & 0.024 & 0.052 \\
\hline Senegal & 0.027 & 0.033 \\
\hline Sierra Leone & 0.016 & 0.085 \\
\hline Tanzania & 0.046 & 0.120 \\
\hline Uganda & 0.060 & 0.209 \\
\hline Zambia & 0.045 & 0.156 \\
\hline Zimbabwe & 0.042 & 0.148 \\
\hline Sample size & \multicolumn{2}{|c|}{368,765} \\
\hline
\end{tabular}

Estimates are calculated using DHS person weights. Conflict is meaured using the definition used in the main model specifications. 
Table A2 Linear regression models predicting ideal family size

\begin{tabular}{|c|c|c|c|c|}
\hline Variable & $\begin{array}{l}\text { Model A1 } \\
\beta(\mathrm{SE})\end{array}$ & & $\begin{array}{l}\text { Model A2 } \\
\beta(\mathrm{SE})\end{array}$ & \\
\hline Conflict (yes) & $\begin{array}{r}-0.0520 \\
(0.0253)\end{array}$ & $*$ & $\begin{array}{c}-0.0669 \\
(0.0259)\end{array}$ & $*$ \\
\hline Age & $\begin{array}{r}-0.0247 \\
(0.0036)\end{array}$ & $* * *$ & $\begin{array}{l}-0.0231 \\
(0.0041)\end{array}$ & $* * *$ \\
\hline $\mathrm{Age}^{2}$ & $\begin{array}{r}0.0005 \\
(0.0001)\end{array}$ & $* * *$ & $\begin{array}{c}0.0004 \\
(0.0001)\end{array}$ & $* * *$ \\
\hline \multicolumn{5}{|l|}{ Education $($ ref $=$ none $)$} \\
\hline Incomplete primary school & $\begin{array}{r}-0.3800 \\
(0.0180)\end{array}$ & $* * *$ & $\begin{array}{l}-0.4165 \\
(0.0210)\end{array}$ & $* * *$ \\
\hline Complete primary school & $\begin{array}{r}-0.7602 \\
(0.0202)\end{array}$ & $* * *$ & $\begin{array}{c}-0.7499 \\
(0.0236)\end{array}$ & $* * *$ \\
\hline Children ever born & $\begin{array}{r}0.2438 \\
(0.0036)\end{array}$ & $* * *$ & $\begin{array}{c}0.2464 \\
(0.0040)\end{array}$ & $* * *$ \\
\hline $\begin{array}{r}\text { Type of residence }(\mathrm{ref}=\text { urban }) \\
\text { Rural }\end{array}$ & $\begin{array}{r}0.4260 \\
(0.0192)\end{array}$ & $* * *$ & $\begin{array}{c}0.4024 \\
(0.0227)\end{array}$ & $* * *$ \\
\hline Sample & $\begin{array}{l}\text { Excludes } \\
\text { countries } \\
\text { without } \\
\text { conflict }\end{array}$ & & $\begin{array}{l}\text { Excludes } \\
\text { regions } \\
\text { without } \\
\text { conflict }\end{array}$ & \\
\hline Province fixed effects & Yes & & Yes & \\
\hline Region-specific linear time trend & Yes & & Yes & \\
\hline $\mathrm{R}^{2}$ & 0.3476 & & 0.3500 & \\
\hline Sample size & 353,946 & & 253,008 & \\
\hline
\end{tabular}

${ }^{* * *} \mathrm{p}<0.001,{ }^{* *} \mathrm{p}<0.01,{ }^{*} \mathrm{p}<0.05, \dagger \mathrm{p}<0.10$. Standard errors clustered on DHS communities. 
Table A3 Logistic regression models predicting any birth in prior year

\begin{tabular}{|c|c|c|c|c|}
\hline \multirow{2}{*}{$\begin{array}{l}\text { Variable } \\
\text { Conflict (yes) }\end{array}$} & \multicolumn{2}{|l|}{$\begin{array}{l}\text { Model A3 } \\
\beta(\mathrm{SE})\end{array}$} & \multicolumn{2}{|c|}{$\begin{array}{l}\text { Model A4 } \\
\beta(\mathrm{SE})\end{array}$} \\
\hline & $\begin{array}{r}-0.0594 \\
(0.0251)\end{array}$ & $*$ & $\begin{array}{l}-0.0673 \\
(0.0253)\end{array}$ & $* *$ \\
\hline Age & $\begin{array}{r}0.3792 \\
(0.0058)\end{array}$ & $* * *$ & $\begin{array}{c}0.3761 \\
(0.0068)\end{array}$ & $* * *$ \\
\hline $\mathrm{Age}^{2}$ & $\begin{array}{r}-0.0091 \\
(0.0001)\end{array}$ & $* * *$ & $\begin{array}{l}-0.0090 \\
(0.0001)\end{array}$ & $* * *$ \\
\hline Education $($ ref $=$ none $)$ & & & & \\
\hline Incomplete primary school & $\begin{array}{r}-0.0775 \\
(0.0181)\end{array}$ & $* * *$ & $\begin{array}{l}-0.0824 \\
(0.0209)\end{array}$ & $* * *$ \\
\hline Complete primary school & $\begin{array}{r}-0.0799 \\
(0.0191)\end{array}$ & $* * *$ & $\begin{array}{l}-0.0905 \\
(0.0222)\end{array}$ & $* * *$ \\
\hline Children ever born & $\begin{array}{r}0.4842 \\
(0.0048)\end{array}$ & $* * *$ & $\begin{array}{c}0.4804 \\
(0.0056)\end{array}$ & $* * *$ \\
\hline $\begin{array}{r}\text { Type of residence }(\mathrm{ref}=\text { urban }) \\
\text { Rural }\end{array}$ & $\begin{array}{r}0.1503 \\
(0.0183)\end{array}$ & $* * *$ & $\begin{array}{c}0.1268 \\
(0.0217)\end{array}$ & $* * *$ \\
\hline Sample & $\begin{array}{l}\text { Excludes } \\
\text { countries } \\
\text { without } \\
\text { conflict }\end{array}$ & & $\begin{array}{l}\text { Excludes } \\
\text { regions } \\
\text { without } \\
\text { conflict }\end{array}$ & \\
\hline Province fixed effects & Yes & & Yes & \\
\hline Region-specific linear time trend & Yes & & Yes & \\
\hline Pseudo $\mathrm{R}^{2}$ & 0.1541 & & 0.1513 & \\
\hline Sample size & 353,946 & & 253,008 & \\
\hline
\end{tabular}

${ }^{* * *} \mathrm{p}<0.001,{ }^{* *} \mathrm{p}<0.01,{ }^{*} \mathrm{p}<0.05, \dagger \mathrm{p}<0.10$. Standard errors clustered on DHS communities. 
Table A4 Coefficient estimates from country-specific linear regression models predicting ideal family size

\begin{tabular}{lrrl}
\hline Country & \multicolumn{1}{l}{$\beta$} & & $(\mathrm{SE})$ \\
Angola & 0.5569 & $*$ & $(0.2669)$ \\
Burundi & -0.0025 & & $(0.0464)$ \\
Cameroon & 1.4915 & $* * *$ & $(0.2582)$ \\
Dem. Rep. Congo & -0.3398 & $\dagger$ & $(0.1741)$ \\
Eswatini & -0.1159 & & $(0.1006)$ \\
Ethiopia & 0.0293 & & $(0.1825)$ \\
Ghana & 0.0571 & & $(0.1111)$ \\
Guinea & -0.2233 & & $(0.1797)$ \\
Kenya & -0.0982 & $\dagger$ & $(0.0515)$ \\
Lesotho & 0.0661 & & $(0.0756)$ \\
Liberia & -0.3018 & & $(0.2548)$ \\
Madagascar & -0.2484 & $*$ & $(0.1152)$ \\
Malawi & -0.0295 & & $(0.0609)$ \\
Mali & -0.0822 & & $(0.3624)$ \\
Namibia & -0.2936 & $*$ & $(0.1382)$ \\
Nigeria & -0.1209 & $\dagger$ & $(0.0669)$ \\
Rwanda & 0.3104 & $*$ & $(0.1535)$ \\
Senegal & -0.4171 & $*$ & $(0.1937)$ \\
Sierra Leone & -0.0494 & & $(0.1109)$ \\
Tanzania & -0.1685 & $*$ & $(0.0755)$ \\
Uganda & 0.0577 & & $(0.0618)$ \\
Zambia & 0.1414 & & $(0.0864)$ \\
Zimbabwe & -0.0895 & & $(0.0829)$ \\
\hline
\end{tabular}

${ }^{* * *} \mathrm{p}<0.001,{ }^{* *} \mathrm{p}<0.01,{ }^{*} \mathrm{p}<0.05, \dagger \mathrm{p}<0.10$. Standard errors clustered on DHS communities. Models control for all variables included in the main specification but replace the region-specific linear time trend within a linear time trend for countries with more than one sample in our data. By default, no time trend is included in models of countries for which there is only a single sample. Burkina Faso and Benin omitted due to a lack of conflict-exposed cases. 
Table A5 Coefficient estimates from country-specific logistic regression models predicting any birth in prior year

\begin{tabular}{|c|c|c|c|}
\hline Country & $\beta$ & & $(\mathrm{SE})$ \\
\hline Angola & -0.2181 & & $(0.1711)$ \\
\hline Burundi & -0.0258 & & $(0.0653)$ \\
\hline Cameroon & -0.2471 & & $(0.5754)$ \\
\hline Dem. Rep. Congo & 0.0210 & & $(0.0970)$ \\
\hline Eswatini & -0.1201 & & $(0.2786)$ \\
\hline Ethiopia & -0.1066 & & $(0.0971)$ \\
\hline Ghana & 0.0449 & & $(0.1809)$ \\
\hline Guinea & 0.1477 & & $(0.1130)$ \\
\hline Kenya & 0.0124 & & $(0.0934)$ \\
\hline Lesotho & -0.1361 & & $(0.2212)$ \\
\hline Liberia & 0.3501 & & $(0.2224)$ \\
\hline Madagascar & -0.0953 & & $(0.1878)$ \\
\hline Malawi & -0.0734 & & $(0.1470)$ \\
\hline Mali & -0.0594 & & $(0.2001)$ \\
\hline Namibia & -0.5181 & $*$ & $(0.2025)$ \\
\hline Nigeria & -0.1569 & $*$ & $(0.0695)$ \\
\hline Rwanda & 0.2546 & & $(0.1659)$ \\
\hline Senegal & -0.3875 & $\dagger$ & $(0.2205)$ \\
\hline Sierra Leone & -0.0514 & & $(0.1504)$ \\
\hline Tanzania & 0.0402 & & $(0.0939)$ \\
\hline Uganda & -0.0815 & & $(0.0608)$ \\
\hline Zambia & -0.1256 & & $(0.1222)$ \\
\hline Zimbabwe & -0.1450 & & $(0.2069)$ \\
\hline
\end{tabular}

${ }^{* * *} \mathrm{p}<0.001,{ }^{* *} \mathrm{p}<0.01,{ }^{*} \mathrm{p}<0.05, \quad \mathrm{p}<<0.10$. Standard errors clustered on DHS communities. Models control for all variables included in the main specification but replace the regionspecific linear time trend within a linear time trend for countries with more than one sample in our data. By default, no time trend is included in models of countries for which there is only a single sample. Burkina Faso and Benin omitted due to a lack of conflict-exposed cases. 
Table A6 Logistic regression models predicting current contraceptive use

\begin{tabular}{|c|c|c|}
\hline Variable & $\begin{array}{c}\quad \text { Model } \\
\beta(\mathrm{SE})\end{array}$ & A5 \\
\hline Conflict (yes) & $\begin{array}{l}-0.0321 \\
(0.0294)\end{array}$ & \\
\hline Age & $\begin{array}{c}0.4182 \\
(0.0050)\end{array}$ & $* * *$ \\
\hline $\operatorname{Age}^{2}$ & $\begin{array}{l}-0.0067 \\
(0.0001)\end{array}$ & $* * *$ \\
\hline \multicolumn{3}{|l|}{ Education (ref = none) } \\
\hline Incomplete primary school & $\begin{array}{c}0.5644 \\
(0.0215)\end{array}$ & $* * *$ \\
\hline Complete primary school & $\begin{array}{c}0.8840 \\
(0.0237)\end{array}$ & $* * *$ \\
\hline Children ever born & $\begin{array}{c}0.1983 \\
(0.0037)\end{array}$ & $* * *$ \\
\hline \multicolumn{3}{|l|}{ Type of residence (ref $=$ urban $)$} \\
\hline Rural & $\begin{array}{l}-0.4267 \\
(0.0210)\end{array}$ & $* * *$ \\
\hline Sample & $\begin{array}{l}\text { Excludes } \\
\text { women wl } \\
\text { gave birth } \\
\text { prior year }\end{array}$ & \\
\hline Province fixed effects & Yes & \\
\hline Region-specific linear time trend & Yes & \\
\hline Pseudo $\mathrm{R}^{2}$ & 0.1925 & \\
\hline Sample size & 305,268 & \\
\hline
\end{tabular}


Table A7 Logistic regression models predicting unmet need for family planning

\begin{tabular}{|c|c|c|}
\hline Variable & $\beta$ (SE) & A6 \\
\hline Conflict (yes) & $\begin{array}{l}-0.0375 \\
(0.0340)\end{array}$ & \\
\hline Age & $\begin{array}{l}-0.1199 \\
(0.0068)\end{array}$ & $* * *$ \\
\hline $\mathrm{Age}^{2}$ & $\begin{array}{c}0.0015 \\
(0.0001)\end{array}$ & $* * *$ \\
\hline \multicolumn{3}{|l|}{ Education (ref = none) } \\
\hline Incomplete primary school & $\begin{array}{c}-0.3982 \\
(0.0204)\end{array}$ & $* * *$ \\
\hline Complete primary school & $\begin{array}{l}-0.8053 \\
(0.0237)\end{array}$ & $* * *$ \\
\hline Children ever born & $\begin{array}{c}0.0892 \\
(0.0046)\end{array}$ & $* * *$ \\
\hline $\begin{array}{r}\text { Type of residence }(\mathrm{ref}=\text { urban }) \\
\text { Rural }\end{array}$ & $\begin{array}{c}0.4733 \\
(0.0258)\end{array}$ & $* * *$ \\
\hline $\begin{array}{c}\text { Province fixed effects } \\
\text { Region-specific linear time trend } \\
\text { Pseudo } \mathrm{R}^{2}\end{array}$ & $\begin{array}{l}\text { Yes } \\
\text { Yes } \\
0.1577\end{array}$ & \\
\hline $\begin{array}{l}{ }^{* * *} \mathrm{p}<0.001,{ }^{* *} \mathrm{p}<0.01,{ }^{*} \mathrm{p}<0.05, \dagger \mathrm{p}< \\
\text { ited to women who report a need for } \\
=157,123) \text { Standard errors clustered } \\
\text { ties. }\end{array}$ & $\begin{array}{l}0.10 \text {. Sam } \\
\text { family plan } \\
\text { on DHS co }\end{array}$ & $\begin{array}{l}\text { ple lim- } \\
\text { ning }(\mathrm{N} \\
\text { mmuni- }\end{array}$ \\
\hline
\end{tabular}


Table A8 Logistic regression models predicting desire for an additional child

\begin{tabular}{|c|c|c|}
\hline Variable & $\beta$ Mode & \\
\hline Conflict (yes) & $\begin{array}{l}-0.0867 \\
(0.0254)\end{array}$ & $* *$ \\
\hline Age & $\begin{array}{c}0.1716 \\
(0.0051)\end{array}$ & $* * *$ \\
\hline Age2 & $\begin{array}{l}-0.0041 \\
(0.0001)\end{array}$ & $* * *$ \\
\hline \multicolumn{3}{|l|}{ Education (ref = none) } \\
\hline Incomplete primary school & $\begin{array}{l}-0.2559 \\
(0.0181)\end{array}$ & $* * *$ \\
\hline Complete primary school & $\begin{array}{l}-0.2574 \\
(0.0196)\end{array}$ & $* * *$ \\
\hline Children ever born & $\begin{array}{c}0.3299 \\
(0.0041)\end{array}$ & $* * *$ \\
\hline $\begin{array}{r}\text { Type of residence }(\text { ref }=\text { urban }) \\
\text { Rural }\end{array}$ & $\begin{array}{c}0.2205 \\
(0.0200)\end{array}$ & $* * *$ \\
\hline $\begin{array}{c}\text { Province fixed effects } \\
\text { Region-specific linear time trend } \\
\text { Pseudo } \mathrm{R}^{2}\end{array}$ & $\begin{array}{c}\text { Yes } \\
\text { Yes } \\
0.2935\end{array}$ & \\
\hline
\end{tabular}




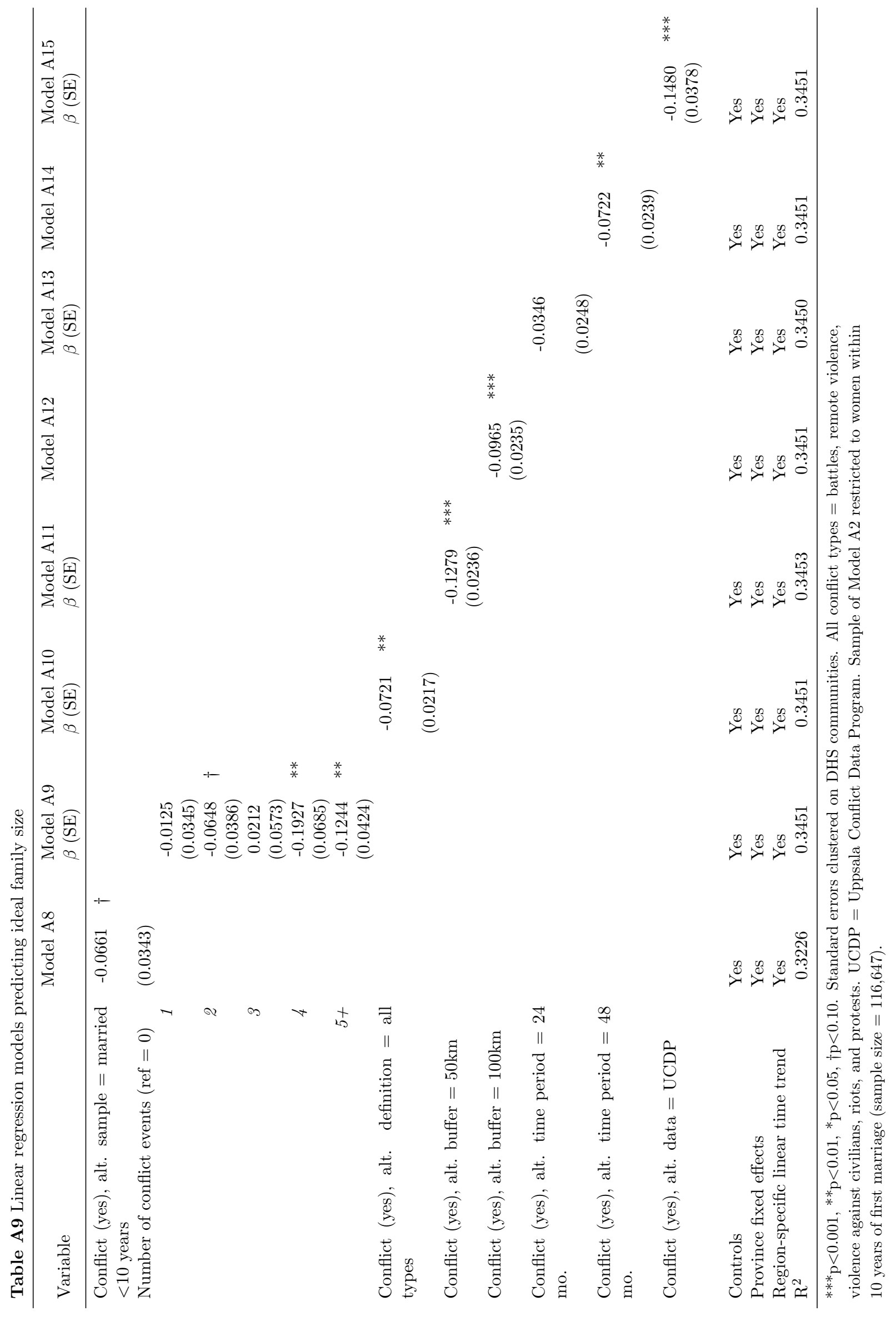




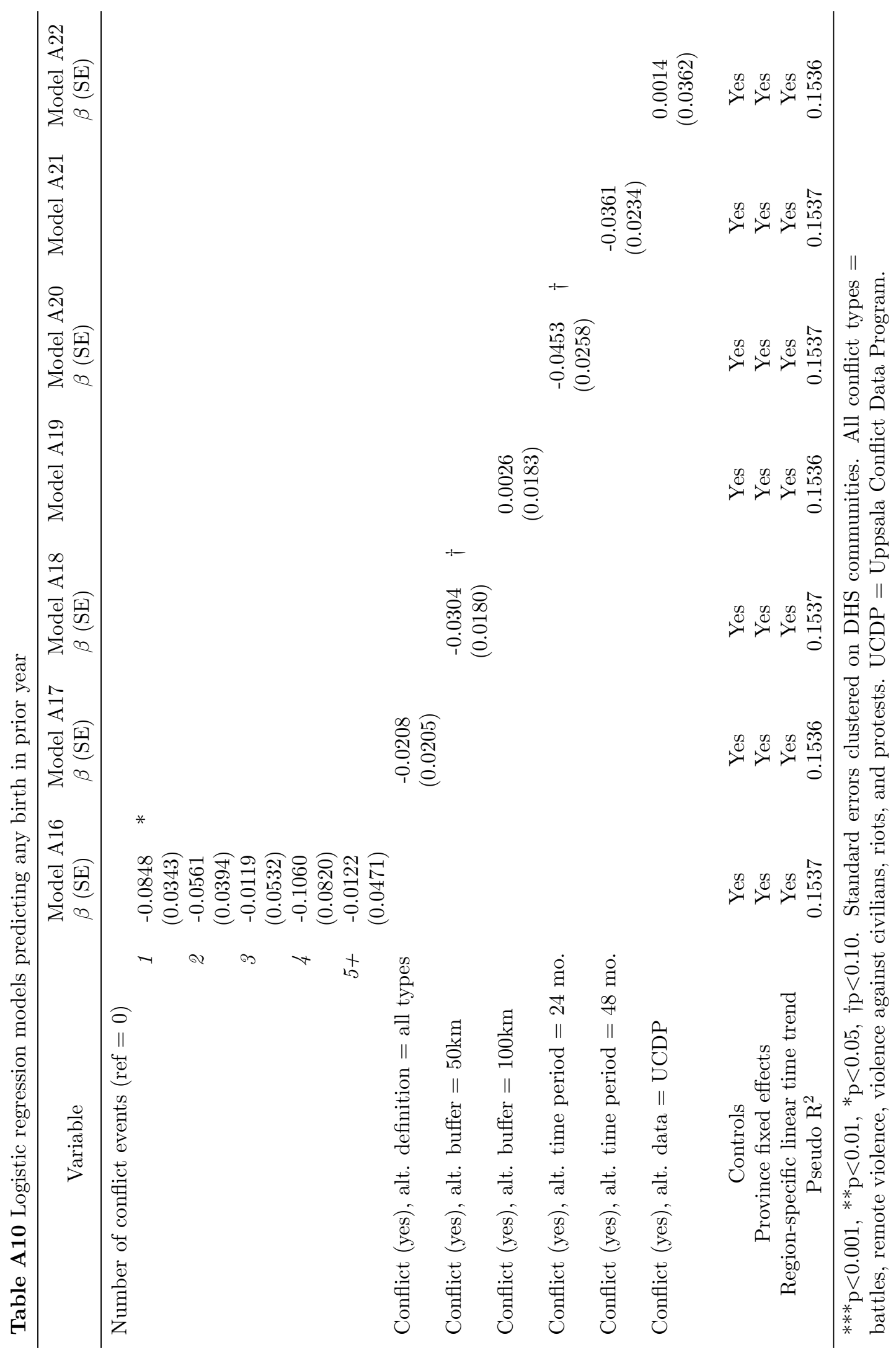

